\title{
Polymeric Micelles in Anticancer Therapy: Targeting, Imaging and Triggered Release
}

\author{
Chris Oerlemans • Wouter Bult • Mariska Bos • Gert Storm • J. Frank W. Nijsen • Wim E. Hennink
}

Received: 3 June 2010 / Accepted: 27 July 2010 / Published online: 20 August 2010

(C) The Author(s) 2010. This article is published with open access at Springerlink.com

\begin{abstract}
Micelles are colloidal particles with a size around 5-100 nm which are currently under investigation as carriers for hydrophobic drugs in anticancer therapy. Currently, five micellar formulations for anticancer therapy are under clinical evaluation, of which Genexol-PM has been FDA approved for use in patients with breast cancer. Micelle-based drug delivery, however, can be improved in different ways. Targeting ligands can be attached to the micelles which specifically recognize and bind to receptors overexpressed in tumor cells, and chelation or incorporation of imaging moieties enables tracking micelles in vivo for biodistribution studies. Moreover, $\mathrm{pH}-$-, thermo-, ultrasound-, or light-sensitive block copolymers allow for controlled micelle dissociation and triggered drug release. The combination of these approaches will further improve specificity and efficacy of micelle-based drug delivery and brings the development of a 'magic bullet' a major step forward.
\end{abstract}

KEY WORDS imaging ' micelles - nanomedicine . theranostics · triggered release

\footnotetext{
C. Oerlemans $\cdot$ W. Bult $\cdot$ M. Bos $\cdot$ J. F. W. Nijsen

Department of Radiology and Nuclear Medicine

University Medical Center

Heidelberglaan 100

3584 CX Utrecht, The Netherlands

G. Storm • W. E. Hennink

Department of Pharmaceutics

Utrecht Institute for Pharmaceutical Sciences, Utrecht University

Utrecht, The Netherlands

C. Oerlemans $(\square)$

P.O. Box 85500, 3508 GA Utrecht, The Netherlands

e-mail: C.Oerlemans@umcutrecht.nl
}

\section{INTRODUCTION}

Cancer is a leading cause of death world-wide and is responsible for approximately $13 \%$ of all deaths, according to the World Health Organization (1). In Europe alone, Ferlay et al. recently estimated that in 20081.7 million cancer deaths occurred, and 3.2 million cancer cases were diagnosed (2). Although prognosis is better now, the large variety of cancer types and metastases makes treatment very difficult. Surgical resection is the treatment of choice, since this treatment is usually curative. Surgery, however, is not an option in many patients due to the tumor size, location and presence of metastases. External beam radiotherapy is also considered a curative treatment option. However, not all tumors are eligible for this therapy due to motion of the tumor-bearing tissue or the adjacency of radiosensitive organs. Another frequently used therapy is systemic chemotherapy, but although chemotherapeutic agents are becoming more and more specific, many of the clinically used chemotherapeutics require high tissue concentrations, which are frequently associated with systemic toxicity. A very promising approach to overcome systemic toxicity is the application of drug-loaded nanosized drug carriers, such as liposomes, polymeric nanoparticles, dendrimers and micelles (3-5). The incorporation of chemotherapeutic agents into nanosized drug carriers has several advantages compared to systemic chemotherapy. First, low-molecularweight drugs are mostly rapidly eliminated by liver and/or kidneys. By loading them in stealth nanoparticles, their bioavailability substantially increases. (6). Second, due to their small size, nanosized drug carriers are passively targeted to the tumors by the enhanced permeability and retention (EPR) effect, leading to a higher drug concentration at the tumor site and decreased toxicity compared with systemic administration (7). Third, hydrophobic drugs can only be administered intravenously (i.v.) after addition of solubilizing 
adjuvants like ethanol or Cremophor EL, which is often accompanied with toxic side effects $(8,9)$. Incorporation of these drugs in micelles avoids the use of adjuvants (10). This review will focus on micelles as a nanosized drug carrier system for cancer therapy and their modifications for tumor targeting, multimodality imaging and triggered release (Fig. 1).

\section{MICELLES}

Micelles are colloidal particles with a size usually within a range of 5-100 nm. Micelles consist of amphiphiles or surface-active agents (surfactants), which exist of two distinct regions: mostly a hydrophilic head-group and a hydrophobic tail. At low concentrations in an aqueous medium, the amphiphiles exist as monomers in true solution, but when the concentration increases, aggregation and self-assembly take place within a narrow concentration window, and micelles are formed (3). The concentration at which micelles are formed is referred to as the critical micelle concentration (CMC). The formation of micelles above their CMC is driven by dehydration of the hydrophobic tails, leading to a favorable state of entropy. Additionally, the formation of Van der Waals bonds allow the hydrophobic polymers to join and to form the micelle core (3). The resulting hydrophilic shell re-establishes hydrogen bond networks with the surrounding water $(3,11)$.

Amphiphilic copolymers usually exhibit a CMC much lower compared to low-molecular-weight surfactants. The CMC of polymeric micelles is typically in the order of $10^{-6}$ to $10^{-7} \mathrm{M}$, while $10^{-3}$ to $10^{-4} \mathrm{M}$ is common for low molecular weight surfactants (12). Due to the low CMC, polymeric micelles remain stable at very low polymer concentrations, which makes them relatively insensitive to dilution, resulting in an enhanced circulation time compared to surfactant micelles (12).

\section{Polymeric Micelles as Drug Delivery Systems}

The bioavailability of anticancer drugs after oral administration is usually low due to reduced absorption (3). Additionally, intravenous administration of these drugs is challenging and requires a formulation with organic solvents and classical surfactants (e.g. the Taxol formulation of paclitaxel from Bristol-Myers Squibb). Solubilization of hydrophobic drugs in the core of micelles can overcome this problem. Polymeric micelles have several advantages over other nanosized drug delivery systems, such as a smaller size as compared to, for instance, liposomes, which is important for, e.g., percutaneous lymphatic delivery or extravasation from blood vessels into the tumor tissue (13). Polymeric micelles are based on block-copolymers with hydrophilic and hydrophobic units that self-assemble in an aqueous environment into structures composed of a hydrophobic core stabilized by a hydrophilic shell. These blocks can be arranged in different ways: A-B type copolymers (diblock copolymer), A-B-A type copolymers (triblock copolymer), and grafted copolymers $(3,11)$. Grafted polymers are branched polymers consisting of one hydrophilic backbone and one to multiple hydrophobic polymer side chains or vice versa.

Polymer selection for micelles is based on the characteristics of both the hydrophilic and the hydrophobic block copolymer. The hydrophilic shell of the micelle provides steric stability and once properly selected avoids rapid uptake by the reticuloendothelial system (RES), resulting in prolonged circulation time in the body (12). Poly(ethylene glycol) (PEG) is the most commonly used hydrophilic polymer. PEG is water soluble, highly hydrated, an efficient steric protector, and biocompatible, and it has low toxicity $(3,11,12,14,15)$.

The hydrophobic block copolymer should possess a high drug loading capacity and good compatibility of the

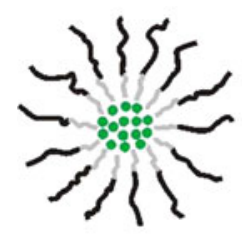

a

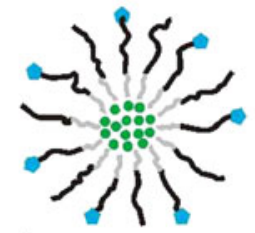

b

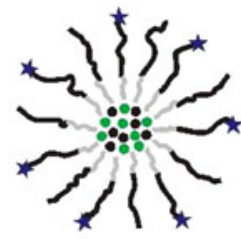

C

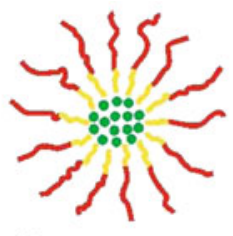

d

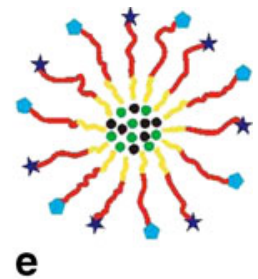

amphiphilic polymer

stimuli-sensitive hydrophilic block

stimuli-sensitive hydrophobic block

Fig. I Schematic drawing of polymeric micelle (a). Micelle conjugated with a targeting ligand (b). Micelle containing an incorporated contrast agent or chelated imaging moieties (c). Micelle modified for triggered drug release (d). Either the hydrophilic or hydrophobic polymer can be rendered thermo/pH/ light/ultrasound-sensitive. Optimized micelle for anticancer therapy, bearing targeting ligands, contrast agents or imaging moieties, therapeutic drugs and polymers suitable for triggered, controlled release $(\mathbf{e})$. 
hydrophobic core with the incorporated drug. One of the possibilities to calculate drug-polymer interactions is the Flory-Huggins theory, which accounts for the forces of interaction between the polymer and the drug and quantifies the difference in the intermolecular interactions of the components in a binary mixture, thereby predicting the compatibility of the drug and polymer (16). Most commonly used polymers for hydrophobic core formation are polyesters, polyethers, and polyamino acids $(15,17)$. Frequently used core-forming molecules are poly(propylene oxide) (PPO), poly(D,L-lactic acid) (PDLLA), poly( $\varepsilon$-caprolactone) (PCL), poly(L-aspartate) and poloxamers (18). The stability (CMC) of polymeric micelles depends on the type and molecular weight of the hydrophobic block. Generally, the more hydrophobic and the higher the molecular weight, the lower the CMC $(14,19)$. In addition, Carstens et al. demonstrated that end-group modification of the coreforming block can be used to stabilize polymeric micelles and to increase drug compatibility and loading, as was shown for $\mathrm{mPEG}$ - $b$-oligo( $\varepsilon$-caprolactone) derivatized with aromatic groups (20,21). Poloxamers exist of a triblock polymer of PEG-PPO-PEG and are commercially available in various compositions under the name Pluronics (BASF Corp.) (12). Different micellar formulations containing these core-forming molecules will be discussed in the next sections.

\section{Polymeric Micelles in Clinical Trials}

Currently, many drug-loaded polymeric micelles for anticancer therapy are under investigation in preclinical studies to improve drug efficacy. Five micellar formulations have been tested in clinical trials (Table I) and will be discussed in more detail.

\section{NKOI 2}

NK012 is a polymeric micellar formulation that consists of a block copolymer of PEG and polyglutamate (PGlu) conjugated with 7-ethyl-10-hydroxy-campothecin (SN-38) (6). SN-38 is a campotothecin analalog and acts as a DNA topoisomerase I inhibitor, but cannot be administered i.v. due to its water-insolubility and high toxicity. SN-38 is covalently coupled to the PGlu segment by the condensation reaction between the carboxylic acid of PGlu and the phenol of SN-38 using 1,3-diisopropylcarbodiimide and $\mathcal{N}$, $\mathcal{N}$-dimethylaminopyridine as coupling agent and catalyst, respectively. Consequently, the PGlu segment is rendered hydrophobically to induce micelle formation (Fig. 2) (26,33). Preclinical in vivo studies with NK012 showed potent antitumor activity in mice. A pharmacokinetic study revealed that the plasma area under the curve (AUC) of micellar SN-38 after i.v. administration (30 mg/ kg) to HT29 tumor-cell-bearing mice was around 200 times higher as compared to CPT-11 (which is hydrolyzed to SN-38 in the circulation) at a dose of $66.7 \mathrm{mg} / \mathrm{kg}$. The $\mathrm{IC}_{50}$ values of NK012 were up to 5.8 times higher than those of free SN38. In addition, the clearance of NK012 in the HT-29 tumors was significantly slower compared to CPT-11 and SN-38. The highest tumor-to-plasma concentration ratio of micellar SN-38 was up to 10 times higher compared to free SN-38. Moreover, NK012 clearance was significantly lower compared to CPT-11 (33,34). Furthermore, a combination of NK012 with 5-fluoruracil (5-FU) showed a significantly higher antitumor effect in human colon cancer xenografts compared to CPT-11/5-FU (35).

From a phase I study with NK012, it was concluded that $37 \mathrm{mg} / \mathrm{m}^{2}$ as a SN-38 equivalent every 3 weeks was the maximum tolerated dose (MTD) in which neutropenia was

Table I Polymeric Micelles in Clinical Trials (22)

\begin{tabular}{|c|c|c|c|c|c|c|}
\hline $\begin{array}{l}\text { Polymeric } \\
\text { micelle }\end{array}$ & Block copolymer & Drug & Diameter & Indication & Clinical phase & Ref. \\
\hline NKOI 2 & PEG-PGlu(SN-38) & SN-38 & $20 \mathrm{~nm}$ & Breast cancer & $\|$ & $(22,23)$ \\
\hline NKI05 & PEG-P(aspartate) & Paclitaxel & $85 \mathrm{~nm}$ & Advanced stomach cancer & $\|$ & $(6,24)$ \\
\hline SPIO49C & Pluronic L6I and FI27 & Doxorubicin & $22-27 \mathrm{~nm}$ & $\begin{array}{l}\text { Adenocarcinoma of oesophagus, } \\
\text { gastroesophageal junction and stomach }\end{array}$ & III & $(\mid 5,25)$ \\
\hline NC-6004 & PEG-PGlu(cisplatin) & Cisplatin & $30 \mathrm{~nm}$ & Solid tumors & $|/| \mid$ & $(26,27)$ \\
\hline \multirow[t]{5}{*}{ Genexol-PM } & PEG-P(D,L-lactide) & Paclitaxel & $20-50 \mathrm{~nm}$ & Breast cancer & IV & $(23,28,29)$ \\
\hline & & & & Pancreatic cancer & $\|$ & $(30,31)$ \\
\hline & & & & $\begin{array}{l}\text { Non-small-cell lung cancer in combination } \\
\text { with carboplatin }\end{array}$ & $\|$ & $(32)$ \\
\hline & & & & $\begin{array}{l}\text { Pancreatic cancer in combination with } \\
\text { gemcitabine }\end{array}$ & $|/| \mid$ & $(23)$ \\
\hline & & & & $\begin{array}{l}\text { Ovarian cancer in combination with } \\
\text { carboplatin }\end{array}$ & $|/| \mid$ & $(23)$ \\
\hline
\end{tabular}




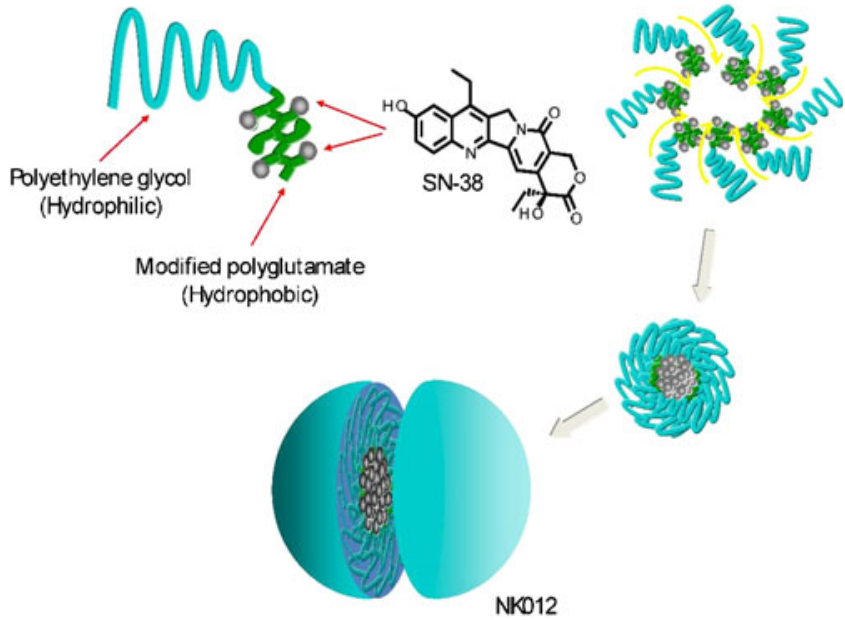

Fig. 2 Schematic structure of $\mathrm{NKO} / 2$, consisting of PEG and partially modified polyglutamate. PEG is used to form the hydrophilic segment, and SN-38 was incorporated into the hydrophobic core of the micelle (33). Reproduced with permission from the American Association for Cancer Research.

found to be the dose-limiting toxicity (DLT) $(26,36,37)$. Currently, the efficacy and safety of NK012 are evaluated in phase II studies in breast cancer patients $(22,23)$.

\section{NKI05}

Paclitaxel (PTX) is frequently used for the treatment of various cancer types, including lung, ovarian and breast cancer $(38,39)$. However, systemically administered PTX causes serious side effects, such as neutropenia and peripheral sensory neuropathy. Additionally, Cremophor EL and ethanol, which are used to solubilize PTX, resulted in a hypersensitive reaction or anaphylaxis in $2-4 \%$ of the patients treated with systemic PTX $(8,22,40)$. Therefore, new PTX formulations are being investigated, such as the NK105 micellar formulation that consists of PEG and modified polyaspartate as hydrophobic block. Half of the carboxylic groups of the polyaspartate block were esterified with 4-phenyl-1-butanol after treatment with the condensing agent 1,3-diisopropylcarbodiimide to increase its hydrophobicity and improve drug incorporation (6,41). PTX is physically incorporated in the core by hydrophobic interactions with the hydrophobic block.

NK105 showed similar cytotoxicity in 12 human tumor cell lines (lung, gastric, oesophagus, colon, breast and ovarian) compared to PTX (41). In preclinical in viwo studies with colon 26-bearing CDF1 mice, the AUG of NK105 was over 50 times higher, while the maximum plasma concentration $\left(\mathrm{C}_{\max }\right)$ in the tumors was three times higher compared to PTX (22). In BALB/c mice bearing subcutaneous HT-29 colon cancer tumors, NK105 administred as a PTXequivalent dose of $25 \mathrm{mg} / \mathrm{kg}$ showed comparable antitumor activity with $100 \mathrm{mg} / \mathrm{kg}$ of free PTX. Additionally, a significant reduction of side effects, caused by Cremophor EL and ethanol after systemic PTX administration, occurred with NK105 (41).

In a phase I study with NK105, less hypersensitivity reactions occurred in patients suffering from pancreatic, bile duct, gastric, and colonic cancers compared to systemic PTX treatment (24). NK105 was administered intravenously for $1 \mathrm{~h}$ every 3 weeks, and the recommended dose of $150 \mathrm{mg} / \mathrm{m}^{2}$ was well-tolerated $(22,24)$. Currently, a phase II study in patients with advanced stomach cancer is underway (6).

\section{SPI049C}

SP1049C consist of a mixture (1:8 w/w ratio) of nonionic Pluronic block copolymers: Pluronic L61 and F127. Doxorubicin is physically encapsulated by noncovalent bonds in the hydrophobic core of the micelles (42). In vitro, it was shown that SP1049C exhibited greater efficacy than doxorubicin against a variety of tumor cell lines (43). In preclinical in vivo studies, SP1049C demonstrated superior antitumor activity, efficacy and an increased AUG in tumor tissue in multiple animal tumor models and in doxorubicinresistant tumors compared to free doxorubicin $(44,45)$. AUC and $\mathrm{C}_{\max }$ in liver, kidney, heart, lung and plasma were similar for SP1049C and free doxorubicin.

The MTD of SP1049C was determined at $70 \mathrm{mg} / \mathrm{m}^{2}$ in a phase I study, around the same as systemic doxorubicin, but SP1049C showed significantly higher antitumor activity and a favorable safety profile compared to doxorubicin. Despite the occurrence of neutropenia as DLT (42), a phase II study concluded that SP1049C was effective as monotherapy in patients suffering from adenocarcinoma of the oesophagus $(46,47)$. SP1049C is currently investigated in phase III in patients with metastatic adenocarcinoma of the oesophagus, gastroesophageal junction and stomach.

\section{NC-6004 (Nanoplatin ${ }^{\mathrm{TM}}$ )}

Cisplatin (cis-dichlorodiammineplatinum[II] or CDDP) is a widely used anticancer agent for treatment of various cancers. However, the use of cisplatin is limited because of severe adverse effects like nephro- or neurotoxicity and drug resistance $(22,48)$. To reduce these side effects and improve efficacy, the micellar formulation NC-6004 was developed. NG-6004 is composed of PEG and a poly $(\gamma$ benzyl L-glutamate)/CDDP complex. In BALB/c mice bearing a human gastic cell line (MKN-4), significant antitumor activity was observed after NC-6004 administration as compared to the control group, but no difference in antitumor activity was observed between the NG-6004 and CDDP administration groups at equivalent dose. However, in Sprague-Dawley rats, a 65-fold increase of the AUC and an 8-fold increase of the $\mathrm{C}_{\max }$ compared to systemic CDDP 
was found. In tumor tissue, an increase in $\mathrm{C}_{\max }$ of 2.5 times was found, and, importantly, NC-6004 was found to significantly reduce nephrotoxicity and neurotoxicity, the dose-limiting factors of CDDP (49).

In a small phase I study, it was shown that NG-6004 was well-tolerated by patients suffering from colorectal carcinoma, upper gastrointestinal cancers, non-small-cell lung carcinoma (NSCLC), melanoma and other tumor types $(26,27)$. Although a small number of patients (17 in total) was included in this study, a DLT phase I/II study with NC-6004 in combination with gemcitabine is in progress with patients suffering from locally advanced pancreatic cancer and metastatic pancreatic cancer (23).

\section{Genexol-PM}

Genexol-PM is a micellar paclitaxel formulation consisting of PEG and poly(D,L-lactic acid) (PDLLA) (28). Preclinical in vivo studies with Genexol-PM demonstrated a 3-fold increase in the MTD and a significantly increased antitumor efficacy compared with free PTX (50). The AUC of Genexol-PM was similar to PTX, but the concentration of PTX was 2-3 times higher in tissues, including liver, spleen, kidneys, lungs, heart and tumor (50).

In phase I studies, a MTD $390 \mathrm{mg} / \mathrm{m}^{2}$ every 3 weeks or $120 \mathrm{mg} / \mathrm{m}^{2}$ every week was determined without the occurrence of hypersensitivity reactions $(28,51)$. In phase II studies, Genexol-PM was found to be effective and safe with high response rates in patients suffering from metastatic breast cancer and advanced pancreatic cancer (29$31,52)$. In patients with metastatic breast cancer, however, hypersensitivity reactions occurred in 8 out of 41 patients $(19.5 \%)$ (29). Moreover, Genexol-PM in combination with cisplatin showed significant antitumor activity and allowed administration of higher dose compared with the Cremophor EL-based formulation in patients with advanced NSCLC. Furthermore, no significant toxicity was found, although hypersensitivity reactions occurred as well (32). Several studies are currently underway, including a phase III and IV study in patients with recurrent breast cancer (23).

\section{POLYMERIC MICELLAR SYSTEMS FOR ENHANCED DRUG DELIVERY}

\section{Active Targeting of Polymeric Micelles}

In addition to passive targeting, micelles can be modified with ligands for active targeting to increase the selectivity for tumor cells and enhance intracellular drug delivery while reducing systemic toxicity and adverse side effects compared to untargeted micelles and systemic chemotherapy (53). The concept behind this approach is based on receptor-mediated endocytosis. When the ligands conjugated to the micelles bind to their specific receptors on the cell membrane, the micelles are internalized by endocytosis (54). In this way, higher intracellular drug concentrations are obtained. Active targeting can be achieved by conjugation of specific ligands, like monocloncal antibodies (mAbs) or their Fab fragments, oligosaccharides or peptides to the shell-forming block (53). This allows micelles to specifically bind to antigens or receptors that are overexpressed on the tumor cells.

Kabanov et al. were one of the first to report an actively targeted micelle-based drug delivery system by developing micelles consisting of Pluronic P85 and murine polyclonal antibodies against $\alpha_{2}$-glycoprotein to deliver the neuroleptic agent haloperidol to the brain (55). The antibodies were anchored to the micelles using a pluronic analog, butylpoly (25)(oxypropylene)poly(20)(oxyethylene) ether of 2hydroxyacetaldehyde (BPEA). Vega et al. addressed mAbbased targeting of micelles in anticancer therapy (56). The epidermal growth factor receptor (EGFR), a transmembrane glycoprotein with an intracellular tyrosine kinase domain, which is overexpressed on the cells of more than one-third of all solid tumors, was targeted with the $\mathrm{mAb}$ C225 (57). This mAb specifically binds to the external domain of EGFR and is therefore suitable for active targeting of micelles to a variety of tumors (58). Next to monoclonal antibodies, folate is an important ligand for active targeting of cancer cells. The folate receptor is overexpressed in many types of cancer, including malignancies of the ovary, brain, kidney, breast, myeloid cells and lung, as it is an essential vitamin for the biosynthesis of nucleotide bases and is consumed in elevated quantities by proliferating cells $(53,59,60)$. Another interesting possibility of micelle-based active targeting is based on ligand-receptor interactions with angiogenesis regulators (61). When tumor cells cluster and reach a size of around $2-3 \mathrm{~mm}$, diffusion of oxygen and nutrients to the tumor is repressed. This induces tumor angiogenesis, which allows tumors to grow beyond their diffusion limit (62). The regulators of this process can be exploited for drug targeting to inhibit angiogenesis and prevent further tumor growth. Integrins represent a large group of structurally related receptors for extracellular matrix (ECM) proteins and immunoglobulin super family molecules and are regarded as key regulators of tumor angiogenesis.

Active targeting to $\alpha_{v} \beta_{3}$ integrin with the micelleconjugated cyclic pentapeptide c(Arg-Gly-Asp-d-Phe-Lys) (cRGDfK) is explored by Nasongkla et al. (63). Currently, several micelle compositions for active targeting in anticancer therapy are investigated in vitro and in vivo, as stated in Table II.

The research on micelles modified with targeting ligands has shown superior results compared to non-targeted 
Table II Micelles for Active Targeting for Anticancer Therapy in Preclinical Models

\begin{tabular}{|c|c|c|c|c|}
\hline Block copolymers & Drug & Active ligand & Target & Results \\
\hline PEG-b-PE & PTX & $\mathrm{mAb} 2 \mathrm{C} 5$ & $\begin{array}{l}\text { nucleosome-restricted } \\
\text { specificity for different cancer } \\
\text { cells }\end{array}$ & $\begin{array}{l}\text { Enhanced accumulation in tumor tissue and significant } \\
\text { tumor weight decrease in C57BL/6J mice (64) }\end{array}$ \\
\hline PEG-b-PG & Dox & mAb C225 & EGF receptor & $\begin{array}{l}\text { More potent than free doxrubicin in inhibiting the } \\
\text { growth of A43 I cells after a } 6 \text { h exposure period } \\
\qquad(56)\end{array}$ \\
\hline PEG-b-PCL & Dox & $\begin{array}{r}\alpha_{v} \beta_{3} \text { ligand } \\
(c R G D f K)\end{array}$ & $\alpha_{v} \beta_{3}$ integrin & $\begin{array}{l}\text { Greatly enhanced internalization in tumor endothelial } \\
\text { cells (human Kaposi's sarcoma) (63) }\end{array}$ \\
\hline \multirow[t]{2}{*}{ PLGA-b-PEG } & Dox & Folate & Folate receptor & $\begin{array}{l}\text { Significant increase in cellular uptake in human } \\
\text { squamous cell carcinoma cell line of the oral cavity } \\
\text { (KB cells) }\end{array}$ \\
\hline & & & & $\begin{array}{l}\text { Increased tumor uptake and significant regression of tumor } \\
\text { volume in a nude mice xenograft model (Fig. 3) (65) }\end{array}$ \\
\hline mPEG-b-PCL & PTX & Folate & Folate receptor & $\begin{array}{l}\text { Endocytosis in MCF-7 cells and increased cytotoxicity } \\
\text { in MCF-7 and HeLa cells (66) }\end{array}$ \\
\hline $\begin{array}{l}\text { PEG }_{3350}-\mathrm{DSPE}: \mathrm{mPEG}_{2300^{-}} \\
\text {DSPE }(1: 100)\end{array}$ & $9-N C$ & Folate & Folate receptor & $\begin{array}{l}\text { Enhanced folate receptor-mediated endocytosis and } \\
\text { increased cytotoxicity in HeLa and SGC790I cells (67) }\end{array}$ \\
\hline $\mathrm{PI} 05$ and PI05/LIOI & PTX & Folate & Folate receptor & $\begin{array}{l}\text { Increased internalization explained the improved cytotoxicity } \\
\text { of the FOL-micellar PTX to tumor cells in MCF-7 } \\
\text { and MCF-7/ADR cells pre-exposed to doxorubicin } \\
\text { (to induce drug resistance) (68) }\end{array}$ \\
\hline DSPE-PEG $3400-S P A$ & I7-AAG & VIP & VPAC, receptors & $\begin{array}{l}\text { Cytotoxicity was similar to free drug and significantly } \\
\text { higher than non-targeted micelles (69) }\end{array}$ \\
\hline
\end{tabular}

PE phosphatidylethanolamine; PG Poly(L-Glu); PCL poly(E-caprolactone); cRGDfK cyclic(Arg-Gly-Asp-d-Phe-Lys); 9-NC 9-nitrocamptothecin; PTX paclitaxel, Dox, doxorubicin; [m]PEG-DSPE [methoxy-]poly(ethylene glycol)-distearoylphosphatidylethanolamine; P Pluronic; 17-AAG 17 -allylamino- 7 demethoxy geldanamycin, VIP vasoactive intestinal peptide; SPA succinimidyl propionate.

micelles. Higher cellular uptake, cytotoxicity and tumor regression was demonstrated, making active targeting an important additional value to passively targeted polymeric micelles for anticancer therapy. However, these systems are

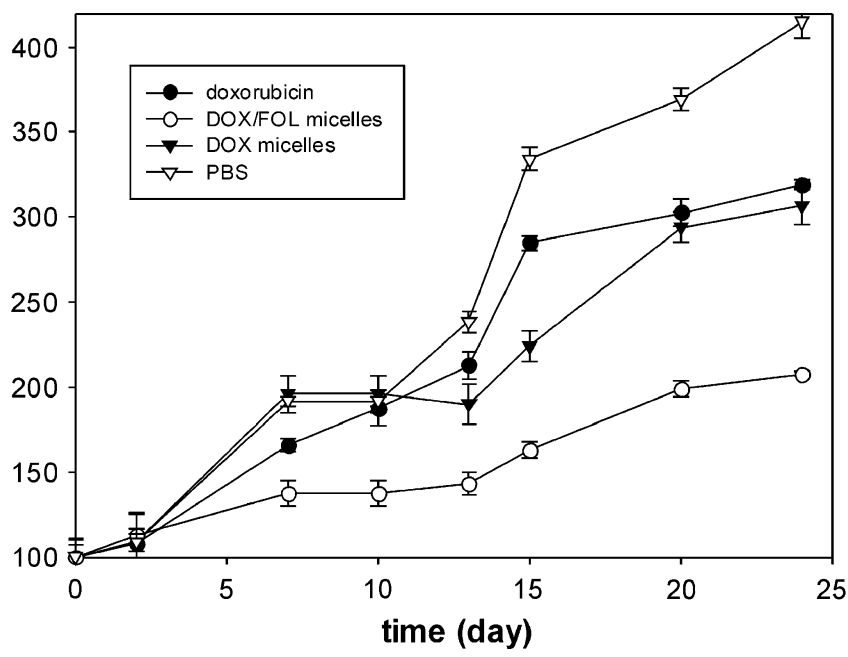

Fig. 3 Tumor volume growth in a nude mice xenograft model after i.v. administration of free doxorubicin, doxorubicin-loaded PLGA-b-PEG micelles and doxorubicin/folate PLGA-b-PEG micelles (65). Reproduced with permission from Elsevier. more complicated since multiple modifications need to be made in one carrier type. Every single modification needs to be optimized, making it difficult and time-consuming to prepare these micelles under GMP conditions which will result in high costs. Furthermore, the circulation half-life might be decreased due to the presence of targeting ligands on the outer shell of the micelles, leading to lower drug concentrations. Consequently, clinical implementation of these systems remains challenging.

\section{Imaging Systems Based on Polymeric Micelles}

\section{Imaging Modalities}

Nuclear imaging, magnetic resonance imaging (MRI) and X-ray computed tomography $(\mathrm{CT})$ play an important role in the diagnosis of cancer and therapy response evaluation. The administration of contrast agents for these imaging modalities greatly enhances the specificity by highlighting the area of interest.

Nuclear imaging allows for the visualization of minute amounts of gamma-emitting isotopes, such as technetium$99 \mathrm{~m}\left({ }^{99 \mathrm{~m}} \mathrm{Tc}\right)$, indium-111 $\left({ }^{111} \mathrm{In}\right)$ and iodine-125 $\left({ }^{125} \mathrm{I}\right)$, for single photon emission computed tomography (SPECT) imaging or positron-emitting isotopes for positron emission 
tomography (PET) imaging, such as fluorine-18 $\left({ }^{18} \mathrm{~F}\right)$, copper-64 $\left({ }^{64} \mathrm{Cu}\right)$ and zirconium- $89\left({ }^{89} \mathrm{Zr}\right)$. Nuclear imaging is the most sensitive imaging modality, requiring an isotope concentration of around $10^{-10} \mathrm{M}$ at the site of interest (70). However, the specificity of nuclear imaging has its drawbacks: it does not allow visualization of the surrounding anatomy, and the temporal resolution is limited (71).

Another imaging modality is MRI, which detects changes in magnetization of hydrogen nuclei $\left({ }^{1} \mathrm{H}\right)$ in the body in a strong magnetic field after application of radiofrequency pulses. Contrast agents used for ${ }^{1} \mathrm{H}$ MRI are usually paramagnetic elements, such as iron, manganese, gadolinium and holmium, that locally alter the magnetization of hydrogen nuclei, thereby enhancing the contrast $(72,73)$. Moreover, fluorine-19 $\left({ }^{19} \mathrm{~F}\right)$ is increasingly gaining attention, since it is a MR-sensitive atom with very low biological abundance. The gyromagnetic ratio of ${ }^{19} \mathrm{~F}$ differs by only about $6 \%$ from ${ }^{1} \mathrm{H}$, while the relative sensitivity is 0.83 , which avoids the need for drastic hardware modifications (74).

CT imaging utilizes differences in absorption of X-rays between different tissues in the body to discriminate between structures in the body. Contrast agents that are used for CT are heavy elements such as iodine, bromine and barium (75). The concentration of contrast agent required at the site of interest is approximately $10^{-2} \mathrm{M}$ (70). The latter two imaging modalities, MRI and CT, allow for simultaneous visualization of both anatomy and the contrast agent. MRI is more suitable for imaging of soft tissue and requires a lower concentration of the contrast agent at the site of interest than CT (76). The development of delivery systems for contrast agents is appropriate for nuclear imaging, CT and MRI, since the contrast agent must selectively reach the site of interest. The development of carrier devices is especially required for MRI and CT contrast agents due to their lower sensitivity compared to nuclear imaging.

\section{Polymeric Micelles for Nuclear Imaging}

Micelles loaded with gamma emitters have been investigated in detail for non-invasive biodistribution studies $(77,78)$. Frequently used nuclides for this purpose are ${ }^{99 \mathrm{~m}} \mathrm{Tc}$ and

${ }^{111} \mathrm{In}$, since these isotopes are easily available, require straightforward labeling procedures and exhibit half-lives that allow for prolonged in vivo imaging (79). ${ }^{99 \mathrm{~m}} \mathrm{Tc}$ can be coupled using a selective $\mathrm{N}$-(N-(3-diphenylphosphinopropionyl)glycyl) cysteine linker (80). Coupling of ${ }^{111}$ In to micelles can be achieved by chelating molecules like diethylenetriaminepentaacetic acid (DTPA) or 1,4,7,10-tetraazacyclododecane1,4,7,10-tetraacetic acid (DOTA), that are conjugated to the polymers. Recently, a biodistribution study using microSPECT/CT was performed with ${ }^{111}$ In-loaded DTPA-PEG-
b-PCL micelles after i.v. injection in tumor-bearing mice (77). Interestingly, the authors observed increased uptake in tumors with large vessels, which was attributed to the EPR effect.

In recent years, the use of PET isotopes with a relatively long half-life such as ${ }^{64} \mathrm{Cu}\left(\mathrm{T}_{1 / 2}=12.7 \mathrm{~h}\right),{ }^{89} \mathrm{Zr}\left(\mathrm{T}_{1 / 2}=78.4 \mathrm{~h}\right)$ and gallium- $67\left({ }^{67} \mathrm{Ga}, \mathrm{T}_{1 / 2}=3.2\right.$ days $)$ has increased. These metals can be coupled in a straightforward fashion using chelators like DTPA and DOTA. The biodistribution of ${ }^{64} \mathrm{Cu}$-containing micelles was investigated in vivo with PET imaging by Pressly et al. using a DOTA-conjugated poly (methyl methacrylate-co-methacryloxysuccinimide-graftpoly(ethylene glycol)) (PMMA-co-PMASI- $g$-PEG) micellar formulation chelated with ${ }^{64} \mathrm{Cu}$, which demonstrated increased blood circulation and low accumulation in excretory organs $(81,82)$.

\section{Polymeric Micelles for MRI}

A lot of work has been conducted for the development of micellar MRI contrast agents. Two approaches that have been frequently used are the incorporation of iron oxide particles in micelles or the use of chelators for complexation of paramagnetic metals to the hydrophilic block of micelleforming block copolymers. The complexation of paramagnetic ions is commonly performed through a chelating moiety, such as DTPA and DOTA. A recent example of this approach is the work of Shiraishi et al., who prepared DOTA-grafted PEG- $b$-poly(L-lysine) micelles with gadolinium and showed a 2-fold relative signal intensity increase in tumor-bearing mice which was maintained for $48 \mathrm{~h}$ (83).

Hydrophobic iron oxide particles have been encapsulated in a number of different micellar formulations to enhance their circulation time. Talelli et al. used micelles consisting of a hydrophobic domain of biodegradable block copolymers of mPEG- $b$-poly[N-(2-hydroxypropyl) methacrylamide dilactate] to encapsulate superparamagnetic iron oxide nanoparticles (SPIONs with a size around $5 \mathrm{~nm}$ ) (Fig. 4) (84). The particles were stable, and the MRI characteristics of the iron oxide particles were retained. Khemtong et al. incorporated SPIONs (size around $10 \mathrm{~nm}$ ) in PEG- $b$ PLA micelles and proposed an off-resonance saturation method for MRI as a useful tool to enhance contrast effects of the superparamagnetic polymeric micelles (85). $\mathrm{Lu}$ et al. prepared mPEG-b-PCL micelles to encapsulate manganese-doped SPIONs (size around $10 \mathrm{~nm}$ ). It was found that the $T_{2}$-weighted signal intensity in mouse liver decreased about $80 \%$ at 5 min after i.v. administration in a time window of $36 \mathrm{~h}$ for enhanced-MRI, which can strongly improve the contrast between small lesions and normal tissues (86).

A relatively new class of MRI contrast agents are fluorine-19 $\left({ }^{19} \mathrm{~F}\right)$-containing contrast agents. ${ }^{19} \mathrm{~F}$ nuclei 


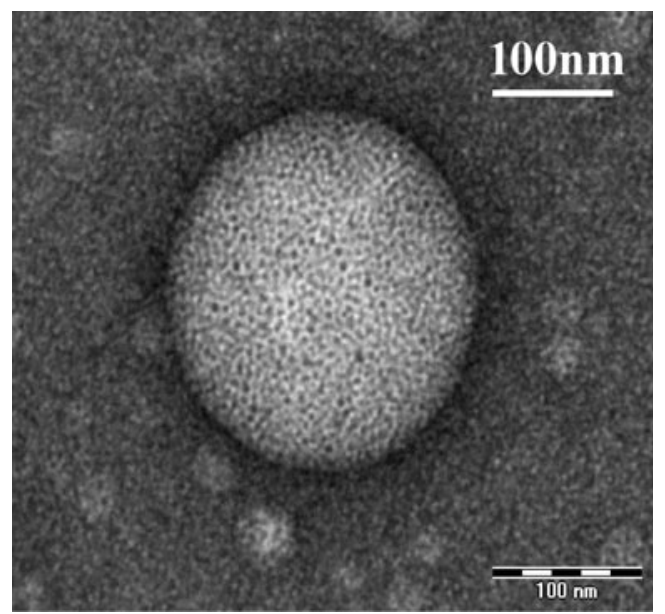

Fig. 4 TEM image of SPION-loaded micelles containing I $\mathrm{mg} / \mathrm{mL}$ SPIONs, and $0.9 \mathrm{mg} / \mathrm{mL}$ mPEG-b-p(HPMAm-Lac2) at high magnification (84). Reproduced with permission from the American Chemical Society.

behave similar to ${ }^{1} \mathrm{H}$ nuclei in a magnetic field and can be visualized on clinical MRI systems (87). The advantage of ${ }^{19} \mathrm{~F}$ MRI is the near absence of a background signal, since the endogenous ${ }^{19} \mathrm{~F}$ concentration in the body is very low. The use of ${ }^{19}$ F-loaded particulate systems for contrast enhancement on MRI has emerged within recent years, since the specific ${ }^{19} \mathrm{~F}$ hardware has become increasingly available on clinical MR scanners (87), allowing clinical evaluation of fluorine particulate systems. Currently, perfluorocarbons like perfluorooctylbromide and perfluoropolyether are the most commonly used ${ }^{19} \mathrm{~F}$ contrast agents $(88,89)$. These compounds, however, have a poor aqueous solubility and are administered as emulsions. As an alternative, self-assembling fluorinated block copolymers have been synthesized. These block copolymers composed of a hydrophilic PEG and a hydrophobic block containing ${ }^{19} \mathrm{~F}$ form micelles in aqueous solution and showed promising imaging results in vitro $(90,91)$, but need to be further investigated in vivo.

\section{Micelles for CT Imaging}

The relatively high concentration of contrast agent required for CT makes this imaging modality less suitable for molecular imaging. However, by extending the circulation time of contrast agents and/or by targeting them to the tissue of interest, this drawback might be overcome. Torchilin et al. developed micelle-based CT iodinecontaining micelles (mPEG- $b$-iodolysine, iodolysine is iodine-substituted poly-L-lysine) which were used as socalled blood pool agents (92). Clinical applications like minimally invasive angiography and image guidance of minimally invasive procedures could benefit from a longcirculation intravascular contrast agent. Micelles modified for tumor imaging using CT have not been reported to date. Nevertheless, CT is particularly suitable to merge with SPECT or PET images. This combines the specificity of nuclear medicine with the anatomical information from CT and will significantly increase the applicability of nuclear imaging (71).

\section{Triggered Release of Polymeric Micelles}

Drug release from micelles is governed by the rate of drug diffusion, the partition coefficient, micelle stability and rate of biodegradation of the copolymers (93). Other factors that influence the release are the drug concentration within the micelles, the length of the hydrophobic polymer, the molecular weight, the physicochemical characteristics of the drug and the localization of the drug within the micelles (94). Drug release from micelles at the targeted area can be enhanced by applying an internal or external trigger. Several methods for triggered release have been described, including $\mathrm{pH}$-sensitive, thermosensitive, ultrasoundsensitive and light-sensitive micelles (95).

\section{pH-Sensitive Micelles}

Differences in $\mathrm{pH}$ between healthy tissue and tumor tissue, as well as the acidic environment in endosomal and lysosomal compartments, can be exploited as an internal stimulus for triggered drug release $(96,97)$. The $\mathrm{pH}$ in healthy extracellular compartments $\left(\mathrm{pH}_{\mathrm{e}}\right)$ is 7.4 , while the intracellular $\left(\mathrm{pH}_{\mathrm{i}}\right)$ is around 7.2. The $\mathrm{pH}$ in tumor tissue is slightly lower, around $\mathrm{pH} 6.8$, due to the high rate of aerobic and anaerobic glycolysis in cancer cells $(17,98)$. Lactate and carbon dioxide, metabolic acid products, diffuse from the cancer cell into the interstitial fluid. However, due to the impaired vasculature, impaired lymphatic drainage, and elevated interstitial pressure, the excretion is retarded, and the metabolic products consequently accumulate (99). In the endosomal and lysosomal compartments the $\mathrm{pH}$ is even lower, around 5-6, which can be utilized for triggered drug release directly into the cells.

The $\mathrm{pH}$-triggered release of drugs can be established by protonation of $\mathrm{pH}$-sensitive polymers that form the hydrophobic core of polymeric micelles at physicological $\mathrm{pH}$. Destabilization occurs when the protonatable groups become charged below the $\mathrm{pK}_{\mathrm{a}}$, leading to repulsion between the polymer chains, which results in micelle dissociation. Many examples of protonation of polymers that trigger micelle destabilization have been reported, including poly(L-histidine), polypyridines, and polysulfonamides (10). Poly(L-histidine) is the most commonly used $\mathrm{pH}$-sensitive component in micellebased $\mathrm{pH}$-triggered release systems since this polymer contains an imidazole ring endowing it with $\mathrm{pH}$-dependent amphoteric properties (100). It has a $\mathrm{pK}_{\mathrm{a}}$ around 6.5 , is 
biodegradable and has low toxicity (98,101-106). Lee et al. prepared micelles based on a triblock copolymer PLA- $b$ PEG- $b$-polyHis, which showed triggered release of doxorubicin when the $\mathrm{pH}$ was lowered from 7.4 to 6.0 . After $5 \mathrm{~h}, 40-50 \%$ of doxorubicin was released at $\mathrm{pH}$ 6.8-6.0, while 60-70\% was released after $24 \mathrm{~h}$. Cytotoxicity was $60 \%$ at $\mathrm{pH} 6.8$ and $74 \%$ at $\mathrm{pH} 6.0$, while only minimal release and cytotoxicity were observed at pH 7.4 (107). Polypyridines like poly(2-vinylpyridine) (P2VP) and poly(4-vinylpyridine) $(\mathrm{P} 4 \mathrm{VP})$ are water-insoluble at neutral or alkalic $\mathrm{pH}$, but become protonated and thus soluble at $\mathrm{pH}<5$ (10,108). A recently developed micellar formulation containing $\mathrm{P} 2 \mathrm{VP}$ has been described by Karanikolas et al. (109). A triblock copolymer of PEO- $b$-P2VP- $b$-PEO was used to demonstrate $\mathrm{pH}$-triggered micelle destabilization. No drug release studies concerning this micelle formulation, however, have been reported yet.

Another mechanism of pH-triggered release is based on the use of acid-labile bonds ( $\mathrm{pH}$-sensitive polymer-drug conjugates) (18,110). Different acid labile bonds such as orthoesters, hydrazones, cis-acotinyl, and acetal have been positioned either in the main chain, at the side chain, or at the terminal of the core-forming block (111-113). For example, Bae et al. prepared micelles based on mPEG- $b$ poly(aspartate hydrazone doxorubicin) where doxorubicin was conjugated to the hydrophobic segments through acidsensitive hydrazone linkers. Selective release of the drug at endosomal $\mathrm{pH}$ and suppressed tumor growth in mice with enhanced therapeutic efficacy and decreased systemic toxicity compared to free doxorubicin was reported (114). Chen et al. prepared micelles with PEG and an acid-labile polycarbonate (96), and demonstrated that the acetal groups of the polycarbonate were hydrolyzed, resulting in paclitaxel or doxorubicin release of $60-70 \%$ after exposure to mildly acidic conditions ( $\mathrm{pH} 5.0-4.0)$ for $10 \mathrm{~h}$. Huang et $a l$. prepared $\mathrm{PEG}-b-\mathrm{P} t \mathrm{NEA}$ micelles based on the orthoester-containing monomer poly(trans- $\mathcal{N}$-(2-ethoxy-1,3dioxan-5-yl)acrylamide) (PtNEA) containing Nile Red dye. The micelles remained stable at $\mathrm{pH} 7.4$ but destabilized in mildly acidic media due to the acid-triggered hydrolysis of the orthoester groups, which increased the hydrophilicity of $\mathrm{P} t \mathrm{NEA}$, resulting in Nile Red release (115). Tang et al. used polymethacrylamide derivative (PMYM)-bearing orthoester side chains as $\mathrm{pH}$-sensitive hydrophobic block to prepare PEG- $b$-PMYM micelles capable of drug release after exposure to mildly acidic conditions (113).

\section{Thermosensitive Micelles}

Thermosensitive micelles are based on the lower critical solution temperature (LCST) or cloud point (CP) of the thermosensitive block of the block copolymer forming micelle. Below the LCST, a thermosensitive polymer is water-soluble, but above this temperature the polymer becomes insoluble due to disruption of hydrogen bonds between water and the polymer chains. The LCST of a polymer can be modulated by introduction of hydrophobic or hydrophilic comonomers. Hydrophobic monomers decrease the LCST, while it is increased by hydrophilic comonomers (10). A frequently studied polymer for the preparation of thermosensitive micelles is poly $(\mathcal{N}$-isopropylacrylamide) (PNIPAAm), which has a reversible and sharp phase transition. It switches from a water-soluble hydrophilic polymer to a hydrophobic insoluble polymer around $32^{\circ} \mathrm{C}(116,117)$. PNIPAAm can be used either as a hydrophilic segment or as a hydrophobic segment of polymeric micelles. As hydrophobic fragment, PNIPAAm is often conjugated to PEG to form stable micelles $(118,119)$. The micelles can be prepared by heating the solution above the LCST of PNIPAAm (10,120). By copolymerizing with hydrophilic monomers the LCST of PNIPAAm can be increased, making it suitable as hydrophilic segment for heat-triggered release. Three monomers that have been investigated in combination with PNIPAAm are acrylamide (AAm), hydroxymethylacrylamide (HMAAm), and dimethylacrylamide (DMAAm). It was found that that copolymers of PNIPAAm with these hydrophilic monomers can have an LCST above body temperature (121). Various preclinical studies have been conducted with thermosensitive micelles, as shown in Table III.

Additionally, thermosensitive micelles have been developed which are not based on PNIPAAm as thermosensitive segment. For instance, micelles based on poly $(\mathcal{N}$-vinylcaprolactam)- $b$-poly(ethylene glycol)-folic acid (PNVCL- $b$ PEG-FA) micelles with an LCST of $33^{\circ} \mathrm{C}$ were prepared. At $37^{\circ} \mathrm{C}$, the micelles showed a slow sustained release profile of the entrapped 5-FU up to $30 \mathrm{~h}$ (around 80\% was released) (128).

Poly( $\mathcal{N}$-(2-hydroxypropyl)methacrylamide) (PHPMAm) is a hydrophilic, non-immunogenic and biocompatible polymer which can be hydrophobically rendered by esterification with lactic acid (129). Soga et al. demonstrated that the lower critical solution temperature (LCST) of PHPMAmlactate can be well-controlled between 10 and $65^{\circ} \mathrm{C}$ by the length of the lactate side group and copolymer composition (130). It was shown that polymeric micelles composed of PEG- $b$-PHPMAm-dilactate gradually dissolved due to hydrolysis of the lactic acid side groups (131). PEG- $b$ PHPMAm-Lac micelles containing $2 \mathrm{mg} / \mathrm{ml}$ paclitaxel which destabilized after around 1 week at physiological conditions were developed (132). In vivo, the antitumor efficacy of this micelle formulation in B16F10 tumorbearing mice after i.v. administration was comparable with the Cremophor EL formulation of paclitaxel but evaded the toxicological side effects originating from Cremophor 
Table III Overview of Thermosensitive Polymeric Micelles, Which Contain PNIPAAm as Thermosensitive Fragment

\begin{tabular}{|c|c|c|}
\hline Micelle type & LCST & Results preclinical studies \\
\hline P(NIPAAm-co-DMAAm)-b-PDLLA & $40^{\circ} \mathrm{C}$ & At $37^{\circ} \mathrm{C}$ slow doxorubicin release, at $42.5^{\circ} \mathrm{C}$ triggered release in vitro $(122)$ \\
\hline P(NIPAAm-co-DMAAm)-b-PLGA & $39^{\circ} \mathrm{C}$ & $\begin{array}{l}\text { Below the LCST stable micelles, enhanced paclitaxel release in vitro at } 39.5^{\circ} \mathrm{C} \\
\text { compared to } 37^{\circ} \mathrm{C}(123) \\
\text { Higher cytotoxicity in vitro at } 39.5^{\circ} \mathrm{C} \text { compared to free paclitaxel }(123) \text { or free } \\
\text { doxorubicin }(124) \text { above LCST }\end{array}$ \\
\hline P(NIPAAm-co-AAm)-b-PDLLA & $41^{\circ} \mathrm{C}$ & $\begin{array}{l}\text { Enhanced cytotoxicity at } 43^{\circ} \mathrm{C} \text { compared to free docetaxel, and lower cytotoxicity } \\
\text { at } 37^{\circ} \mathrm{C} \text {, higher } L D_{50} \text { and higher efficacy in vivo }(125)\end{array}$ \\
\hline PMMA-b-P(NIPAAm-co-PEGMEMA)-b-PMMA & $39^{\circ} \mathrm{C}$ & $\begin{array}{l}\text { Below the LCST the micelles expand, while above the LCST the hydrophilic block shrinks } \\
\text { Release of folic acid (used as model drug) increased at } 41^{\circ} \mathrm{C} \text { compared to } \\
37^{\circ} \mathrm{C} \text { in vitro (I26) }\end{array}$ \\
\hline P(NIPAAm-co-DMAAm)-b-(PDLLA-co-PCL) & $40^{\circ} \mathrm{C}$ & $\begin{array}{l}\text { Significantly increased doxorubicin release in vitro after } 10 \mathrm{~h} \text { exposure to } 41^{\circ} \mathrm{C} \\
\text { compared to temperatures below the LCST }(127)\end{array}$ \\
\hline
\end{tabular}

PDLLA poly(D,L-lactic acid); PLGA poly(D,L-lactide-co-glycolide); MEMA methyl ether methacrylate; PMMA poly(methyl methacrylate); PCL poly ( $\varepsilon$-caprolactone).

EL $(8,9)$. However, no significant accumulation of micelles in tumor tissue was observed after $24 \mathrm{~h}$, probably caused by premature micelle destabilization. Low stability in the systemic circulation is one of the problems that may arise after i.v. administration of polymeric micelles. In vitro studies showed that the addition of either human albumin or serum to drug-loaded micelles substantially decreased their stability, leading to rapid release of the encapsulated drug (133,134). Additionally, the micelles may be diluted below their CMC after i.v. administration, which also leads to premature micelle destabilization (135,136). An increased micellar stability can be established by either physical or chemical cross-linking of the shell, the intermediate layer or the core of the micelles $(137,138)$. This way, the circulation time of the micelles can be enhanced. Crosslinking also enables controlled release of the entrapped drug, whereas the stimuli responsiveness of the micelles is not affected $(139,140)$. Rijcken et al. prepared core-crosslinked thermosensitive micelles based on $\mathcal{N}$-(2-hydroxyethyl) methacrylamide (HEMAm) block copolymers which were derivatized with various monodisperse oligolactates $($ HEMAm-Lac $n)$. Part of the hydroxyl end groups of the lactic acid groups were derivatized with methacrylic acid to allow cross-linking of the micellar core by radical polymerization (137). These core-cross-linked micelles showed an excellent physical stability and a superior circulation profile compared to non-cross-linked micelles. More than 50\% of the micelles still resided in the circulation $6 \mathrm{~h}$ post-injection, and an increased tumour accumulation was observed.

Hence, two promising approaches have been developed regarding thermosensitive micelles. First, micelles consisting of a hydrophilic block copolymer with an LCST above $37^{\circ} \mathrm{C}$ are able to release their content after the induction of mild hyperthermia, which, for instance, can be induced by (focused) ultrasound. Second, stabilized, cross-linked micelles derivatized with lactate side chains are very attractive for controlled release of anticancer drugs at $37^{\circ} \mathrm{C}$ upon i.v. administration.

\section{Ultrasound-Responsive Micelles}

Ultrasound with a frequency higher than $20 \mathrm{kHz}$ can be used to generate ultrasonic waves in tissue (141). In general, exposure of tissue to ultrasound results in two effects: hyperthermia (thermal effects by absorption of energy), and non-thermal effects associated with oscillating or cavitating bubbles (142). A favorable characteristic of ultrasound is noninvasive deep penetration in the body which can be focused and controlled. Additionally, ultrasound can facilitate absorption and membrane passage of drugs (141-144).

Exposure of micelles to ultrasound has been reported for triggered drug release in tumor tissue (142). Several studies suggest that drug release is triggered due to disruption of the carrier and the formation of micropores in cell membranes, facilitating passive diffusion and intracellular accumulation of the drug (145). The abrupt compression and expansion of the fluid in the shockwave caused by the collapse of microscopic gas bubbles that are present in the body results in shear stress which in turn disrupts micelles and permeabilizes cell membranes (143). The increased permeability of the cell membrane is induced by cavitation, defined as the oscillation of bubbles in an acoustic field, and allows direct passage of the therapeutics into the cytosol (146).

When ultrasound is applied, several factors should be considered: time of application, application procedure (continuous or pulsed with different exposure times), lipophilicity and concentration of the drug, ultrasound frequency, and power density $(145,147)$. The appropriate frequency, power density and pulse duration depend on the 
location of the tumor. High frequencies (1 of $3 \mathrm{MHz}$ ) have higher power densities and can be more narrowly focused, making them suitable for small superficial tumors. Low frequencies $(20-100 \mathrm{kHz})$, on the other hand, are able to penetrate deeper into the body and are therefore more appropriate for deeply located tumors, but can also damage healthy tissue and organs due to a strong cavitation effect (148-150).

The most frequently studied micelles for ultrasoundtriggered release are based on Pluronic $\mathrm{P} 105$, a $\mathrm{PEO}_{37^{-}}$ $\mathrm{PPO}_{56}-\mathrm{PEO}_{37}$ block copolymer (150). These micelles showed increased drug release upon exposure to ultrasound (142,151), which makes them attractive drug delivery systems for triggered release. However, upon administration, Pluronic P105-based micelles dissociated quickly, which resulted in micelle disintegration and premature drug release (152). Therefore, it is important to increase their stability, which can be achieved by adding stabilizing agents. PluroGel $^{\mathrm{TM}}$ is an example of Pluronic P105 micelles stabilized with the cross-linking agent $\mathcal{N}, \mathcal{N}$-diethylacrylamide (NNDEA) $(149,153)$. The formed interpenetrating network is a thermally reversible nanogel which expands below $31^{\circ} \mathrm{C}$ and enables drug loading at room temperature. When the temperature increases above $31^{\circ} \mathrm{C}$, the network contracts and collapses into a tight hydrophobic core in which the drug is entrapped. Husseini et al. demonstrated that although the micellar formulation was stabilized with NNDEA, the release of doxorubicin in response to $70 \mathrm{kHz}$ ultrasound was similar compared to non-stabilized P105 micelles (148,151,154-157). Nelson et al. introduced a colon carcinogen tumor cell (DHD/K12/TRb) into the hind limbs of BDIX rats which were treated weekly with stabilized micelles or free doxorubicin by i.v. administration (153). Application of 20 and $70 \mathrm{kHz}$ low-frequency ultrasound significantly reduced the tumor size as compared to noninsonated controls. Additionally, a significant reduction was also found in tumors treated with free doxorubicin, which can be ascribed to the enhancement of passive diffusion as is associated with the use of ultrasound (145). Micelles based on Pluronic P105 can also be stabilized by introducing a PEG-diacylphospholipid like 1,2-distearoyl-sn-glycero-3phosphoethanolamine- $\mathcal{N}$-[methoxy-(polyethylene glycol)2000] $\left(\mathrm{mPEG}_{2000}\right.$-DSPE) in a $1: 1$ ratio to decrease the CMC, as was demonstrated by Gao et al. $(142,149,153,158-$ 160). In vivo studies demonstrated that exposure of both stabilized and non-stabilized Pluronic P105 micelles loaded with doxorubicin or 5-FU to low-frequency ultrasound resulted in enhanced drug concentrations in tumor tissue and a significant decrease in tumor volume compared to mice which were not treated with ultrasound. However, the release of doxorubicin from non-stabilized Pluronic P105 micelles was around 3 times higher as compared to stabilized micelles $(10 \%$ and $3 \%$, respectively), and they were more susceptible to the shearing forces associated with cavitation $(142,159,161,162)$. Nevertheless, drug release was observed each time ultrasound was applied. Therefore, pulsed ultrasound can theoretically release all of the encapsulated drug from the stabilized micelles, while their stability in the circulation is much better as compared to non-stabilized micelles (146). Non-Pluronic micelles have also been investigated for ultrasound-triggered release, as summarized in Table IV.

Although promising studies have been performed with low-frequency ultrasound-sensitive micelles, low-frequency ultrasound cannot be focused and results in damage of healthy tissues, which restricts its practical clinic use (164). Cavitation also occurs with high ultrasonic intensities, although this effect is less than low-frequency ultrasound. High-intensity focused ultrasound (HIFU) has been studied extensively in combination with MRI, and, importantly, recent studies have shown that ultrasound-induced hyperthermia can be controlled using MRI thermometry

Table IV Overview of Non-pluronic Ultrasound-Responsive Micelles

\begin{tabular}{|c|c|}
\hline Micelle type & Characteristics and results \\
\hline PEG-b-PBLA & $\begin{array}{l}\text { 8-fold increase of intracellular doxorubicin uptake after } 30 \text { s ultrasound application (I MHz) in mice bearing } \\
\text { ovarian cancer (A2780) cells (I 59) }\end{array}$ \\
\hline \multirow[t]{2}{*}{ PEO-b-PNHL } & Micelle half-life in the systemic circulation can be tailored by composition modifications $(|42| 6 \mid)$, \\
\hline & $\begin{array}{l}\text { Lactate esters are hydrolyzed, the } \mathrm{PNHL} \text { block becomes hydrophilic, and doxorubicin was } \\
\text { released after } 70 \mathrm{kHz} \text { application }(|42,16|)\end{array}$ \\
\hline PEO-b-PTHPMA & Ultrasound ( I MHz) application resulted in hydrolysis of acetal bonds and cleavage of THP groups (I63) \\
\hline PEG-b-PLLA & $\begin{array}{l}\text { Irreversible break of PEG and PLA linkage after ultrasound application }(\mathrm{I} . \mathrm{I} \mathrm{MHz}) \text { by cavitation and subsequent } \\
\text { Nile Red release ( } 164)\end{array}$ \\
\hline PEG-co-PLA-tocopherol & $\begin{array}{l}\text { Improved drug uptake after } 30 \text { s ultrasound application }(\mathrm{I} \mathrm{MHz}) \text { in tumor in mice and regression of drug } \\
\text { resistant breast cancer (MCF-7/ADM tumors) }(146,149)\end{array}$ \\
\hline
\end{tabular}

PBLA poly( $\beta$-benzyl-L-aspartate); PNHL copolymer of poly(N-isopropylacrylamide) and polylactate esters of hydroxyethyl metacrylate (HEMA-lactate); PTHPMA poly(tetrahydropyranyl-2-methacrylate); PLLA poly(L-lactic acid). 
$(165,166)$, which makes this technique suitable for triggered drug release from both thermosensitive- and ultrasoundsensitive micelles. We therefore consider high-frequency focused ultrasound preferable over low-frequency ultrasound for triggered drug release.

\section{Light-Responsive Micelles}

Light can be used as an external stimulus for micelle disintegration and offers the possibility to locally destabilize micelles in the body (167). This increases the specificity of drug delivery. Particularly, ultraviolet (UV) and near infrared (NIR) light can be used to trigger release. However, UV light is not able to penetrate deeply into the body because of absorption by the skin, yet it can trigger drug release for topical treatment of the skin and mucosa. NIR is able to penetrate deeper, up to $10 \mathrm{~cm}$, in the body, because hemoglobin (the principal absorber of visible light), water and lipids (the principal absorbers of infrared light) have low absorption in the NIR region (650$900 \mathrm{~nm})(167-169)$. Micelles can be rendered light-sensitive and thus deliver drugs in response to light by incorporation and/or conjugation of a chromophore structure in/to the hydrophobic polymer (167). When light-sensitive micelles are illuminated, the hydrophilic/hydrophobic balance changes and the micelles dissociate. In general, there are two types of reactions associated with light-induced micelle destabilization. First, the photoreaction of a chromophore can change the polarity of the hydrophobic polymer reversibly which causes subsequent micellar destabilization. When the photoreaction stops, the initial polarity is returned and the micelles are re-established (Table V) $(167,170)$.

A second photoreaction that might occur upon illumination of light-sensitive micelles with UV or NIR is established by the irreversible cleavage of a photolabile group from the hydrophobic block, converting it into a hydrophilic polymer leading to micellar destabilization (167). Table VI summarizes irreversible light-response micelles that have been investigated.

Although promising results have been achieved with destabilization of micelles upon light exposure, no in vivo studies with drug-loaded micelles have yet been performed.

\section{MULTIFUNCTIONAL POLYMERIC MICELLES}

Currently, increasing attention in micelle-based anticancer therapy is given to multifunctional micelles containing at least two out of three features regarding targeting ligands, imaging agents or triggered release. The combination of imaging agents and triggered release enables micelle tracking in the body and on-command triggered release once the micelles reach their target area, while combining active targeting and triggered release results in more efficient drug delivery. For multifunctional micelles, only $\mathrm{pH}$ sensitivity as triggered release mechanism has been investigated in combination with active targeting. Kataoka et al. prepared doxorubicin-loaded, $\mathrm{pH}$-sensitive polymeric micelles equipped with folate-ligands. In an in vitro study with human pharyngeal cancer cells, cytotoxicity of folatebound micelles was 8-fold higher than non-targeted $\mathrm{pH}$ sensitive micelles (180). An in vivo study with mice showed that after i.v. administration the folate-equipped micelles resulted in a therapy that was substantially better than that of free doxorubicin and micelles without folate conjugation (181). The research group of Bae successfully prepared $\mathrm{pH}$ sensitive micelles bearing targeting ligands. For example, doxorubicin-loaded poly(L-histidine)- $b$-PEG- $b$-PLLA micelles were conjugated with folic acid for active targeting to overcome multidrug resistance (182). It was shown that when the micelles were internalized by folate receptor-

Table V Overview of Light-Sensitive Chromophores, Which Enable Reversible Light Response

\begin{tabular}{|c|c|}
\hline Chromophore & Light response \\
\hline Cinnamoyl & Ionization: isomerization to more hydrophilic species due to the electric charge generation or dimerization $(171,172)$ \\
\hline Azobenzene & $\begin{array}{l}\text { Isomerization: upon UV irradiation, the compound in the trans conformation, having no dipole moment, is reversibly } \\
\text { converted to the cis conformation with a dipole moment }(167,170,173) \\
\text { Examples are: NNDMA, MOAB and the light-sensitive micellar formulation with hydrophilic P(tBA-co-AA) and } \\
\text { hydrophobic PAzoMA }(167,173)\end{array}$ \\
\hline Spirobenzopyran & $\begin{array}{l}\text { Zwitterion: colorless spiropyran is converted into colored merocyanin upon UV (365 } \mathrm{nm}) \text { irradiation and re-established } \\
\text { under visible light }(620 \mathrm{~nm})(17 \mathrm{I})\end{array}$ \\
\hline Diarylethenes & Photocyclization: configuration of a ring system as a result of the formation of one new single bond ( 174$)$ \\
\hline Fulgides & Photochromism: switch from open colorless state to colored cyclic state (I75) \\
\hline Overcrowded alkenes & Chiroptical switch: switch to another conformation (176) \\
\hline
\end{tabular}

NNDMA N,N-dimethylacrylamide; MOAB methacryloyloxyazobenzene; P(tBA-co-AA), poly(tert-butyl acrylate-co-acrylic acid); PAzoMA poly(azobenzene methacrylate). 
Table VI Overview of Irreversible Light-Responsive Micelles and Their Cleavage Mechanism

\begin{tabular}{llll}
\hline Micelle composition & Photolabile group & Light source & Cleavage mechanism \\
\hline PEG-PPyMA & I-pyrenylmethyl & UV & Pyrenylmethyl ester is cleaved: PPyMA $\rightarrow$ PMA + I-pyrenemethanol ( I 67, I 77) \\
PEG-b-PNBMA & 2-nitrobenzylmethyl & UV/NIR & PNBMA $\rightarrow$ PMA + 2-nitrosobenzoldeyde ( I 67) \\
PEG-b-P(MA-DEACM) & DEACM & UV/NIR & Cleavage DEACM (I78) \\
n/a & 3,5-DMB & UV & Cleavage ester of 3,5-DMB (I79) \\
\hline
\end{tabular}

PPyMA poly(I-pyrenylmethyl methacrylate); PMA poly(methacrylic acid); PNBMA poly(2-nitrobenzylmethyl methacrylate); DEACM coumarin chromophore (7-[diethylamino]coumarin-4-yl)methyl; 3,5-DMB 3,5-dimethoxybenzoin; n/a not applicable.

mediated endocytosis, the poly(L-histidine) block became protonated at endosomal $\mathrm{pH}$, resulting in micelle destabilization and subsequent release of the drug into the cytosol by disruption of the endosomal membrane $(104,182)$. In this way, drug interaction with the P-glycoprotein transporter, present in the cellular membrane and the major cause of multidrug resistance, is minimized (98). In mice, these $\mathrm{pH}$ sensitive micelles had significantly better antitumor effects as compared to $\mathrm{pH}$-insensitive micelles $(104,182)$. The same group also developed a pH-dependent doxorubicin-loaded poly(L-histidine)- $b$-PEG- $b$-PLLA micelle formulation by conjugating biotin, an example of a non-specific cell-penetrating peptide, to the hydrophilic shell of the micelles (101). In MCF-7 cells, internalization of biotin-conjugated micelles was significantly higher at $\mathrm{pH} 7.0$ as compared to $\mathrm{pH}$ 7.4. At $\mathrm{pH}$ 6.8, micelle destabilization and enhanced doxorubicin release was observed.

A more advanced approach is defined by an active targeting micellar system shielded with a $\mathrm{pH}$-sensitive compound. Bae's group conjugated trans-acting activator of transcription (TAT) peptide to PLLA- $b$-PEG- $b$-PSD micelles for intracellular delivery of drugs in tumor cells. At pH 7.4, the anionic PSD (poly(methacryloyl sulfadime- thoxine)) is complexed with cationic TAT coupled to the distal end of the PEG block. When the $\mathrm{pH}$ decreases below 6.8, the sulfonamide groups lose their charge and detach, resulting in micelles which expose TAT at their surface, which subsequently facilitates cellular uptake of the micelles. This is referred as the 'pop-up' mechanism (Fig. 5) (183) and reduces the circulation half-life problems as observed with active targeting systems, since the micelles only expose the TAT peptides at the tumor site. In vitro studies with MCF-7 cells and in vivo studies in BALB/c mice with drug-resistant solid tumors resulted in effective treatment and significant tumor regression (184). Yang et $a l$. investigated folate-based active targeting of PEG- $b$-poly (malic acid)-co-poly( $\varepsilon$-caprolactone) (PEG- $b$-PMA-co-PCL) micelles in combination with $\mathrm{pH}$ responsiveness. In mouse mammary carcinoma cells, doxorubicin uptake by tumor cells and cytotoxicity were enhanced compared to nontargeted micelles (185). Wu et al. prepared $\mathrm{pH}$-sensitive polymeric micelles which were conjugated with AP peptide (CRKRLDRN, which has a very specific binding affinity to IL-4 receptors of atherosclerotic plaques and breast tumor tissue), and demonstrated a significant increase in delivery of doxorubicin and tumor reduction in MDA-MB231
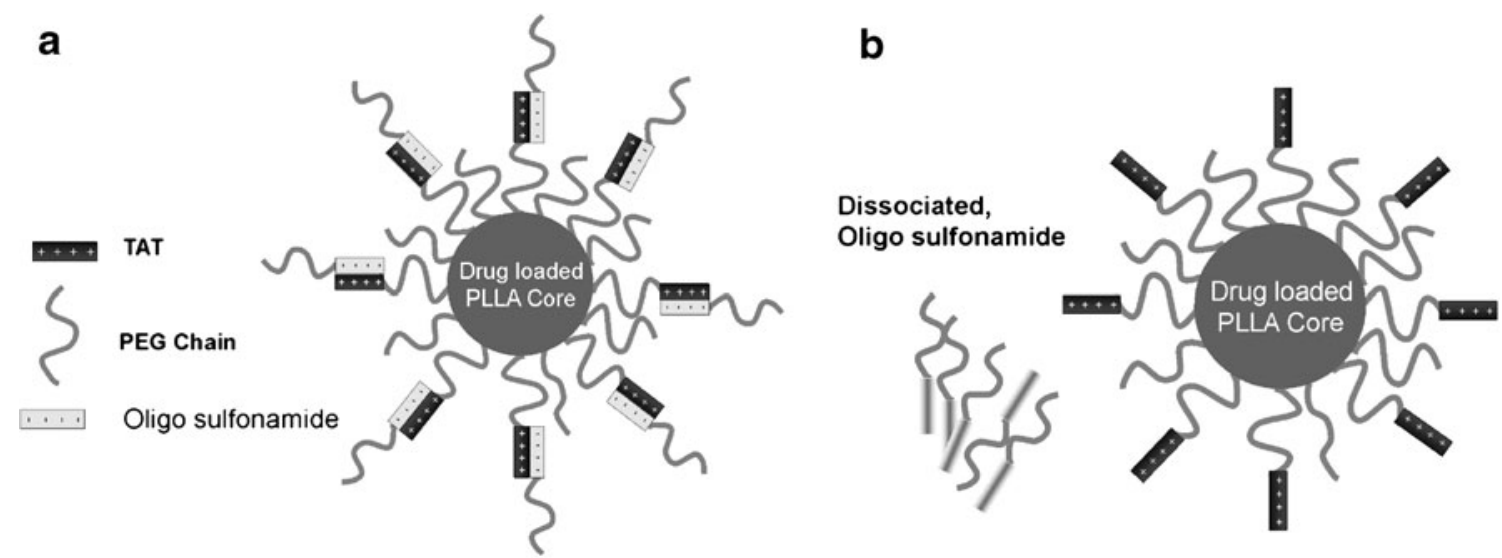

Fig. 5 Schematic model of the 'pop-up' mechanism-based micelle formulation. The carrier system consists of two components, a PLLA-b-PEG micelle conjugated to TAT and a pH sensitive diblock polymer PSD-b-PEG. At normal blood $\mathrm{pH}$, the sulfonamide groups are negatively charged, binding via electrostatic interactions to the TAT units, thereby shielding these groups (a). When the system experiences a decrease in $\mathrm{pH}$ (near tumor) sulfonamide looses charge and detaches, thus exposing TAT for interaction with tumor cells (b) (I 83). Reproduced with permission from Elsevier. 
human breast tumor-bearing mice compared to nontargeted micelles and free doxorubicin (186). As was shown in these studies, the combination of active targeting and triggered release resulted in superior cytotoxicity and antitumor activity as compared to non-multifunctional micelles. However, it would be interesting to also include other options for triggered release in combination with active targeting. For instance, temperature- or ultrasoundsensitive micelles can be triggered to release their content after exposure to HIFU and, if combined with active targeting, would result in an efficient, well-controlled drug delivery system.

Another combination of strategies in micelle-based drug delivery is active targeting and imaging. In this way, the micelles can be tracked throughout the body, and the micelle deposition at the target site can be determined. Rossin et al. tracked the biodistribution of poly(acrylic acid$b$-methyl acrylate) (PEG-b-PAA-b-PMA) shell cross-linked micelles (SCKs) with autoradiography of the ${ }^{64} \mathrm{Cu}$-labeled micelles, but did not find any significant higher uptake of folate-conjugated micelles compared to non-targeted micelles in $\mathrm{KB}$ tumor cell xenograft-bearing mice. This was ascribed to the presence of necrotic areas in big, fastgrowing tumors, which hampered extravasation of the micelles into tumor tissue (187). However, folate receptormediated uptake of the SCKs in very small tumors was observed, suggesting the possible use of radiolabeled SCKs as drug delivery systems for imaging and treatment of earlystage tumors. EGF-receptor-targeted PEG- $b$-PCL micelles labeled with ${ }^{111}$ In were developed by Lee et al. (77). Images taken with micro-SPECT/CT showed that the intratumoral distribution of both targeted and non-targeted micelles was heterogeneous and positively correlated with tumor vascularization. Enhanced accumulation in tumor tissue was observed with the targeted micelles (T-BCM) compared to non-targeted micelles (NT-BCM) (Fig. 6). In a recent in vitro study, Guthi et al. described a multifunctional methoxy-terminated PEG- $b$-PDLLA micelle system that is encoded with a lung cancer-targeting peptide (LCP) and loaded with SPIONs together with doxorubicin for MR imaging and therapeutic delivery, respectively (188). A significantly increased cell targeting, micelle uptake, superb

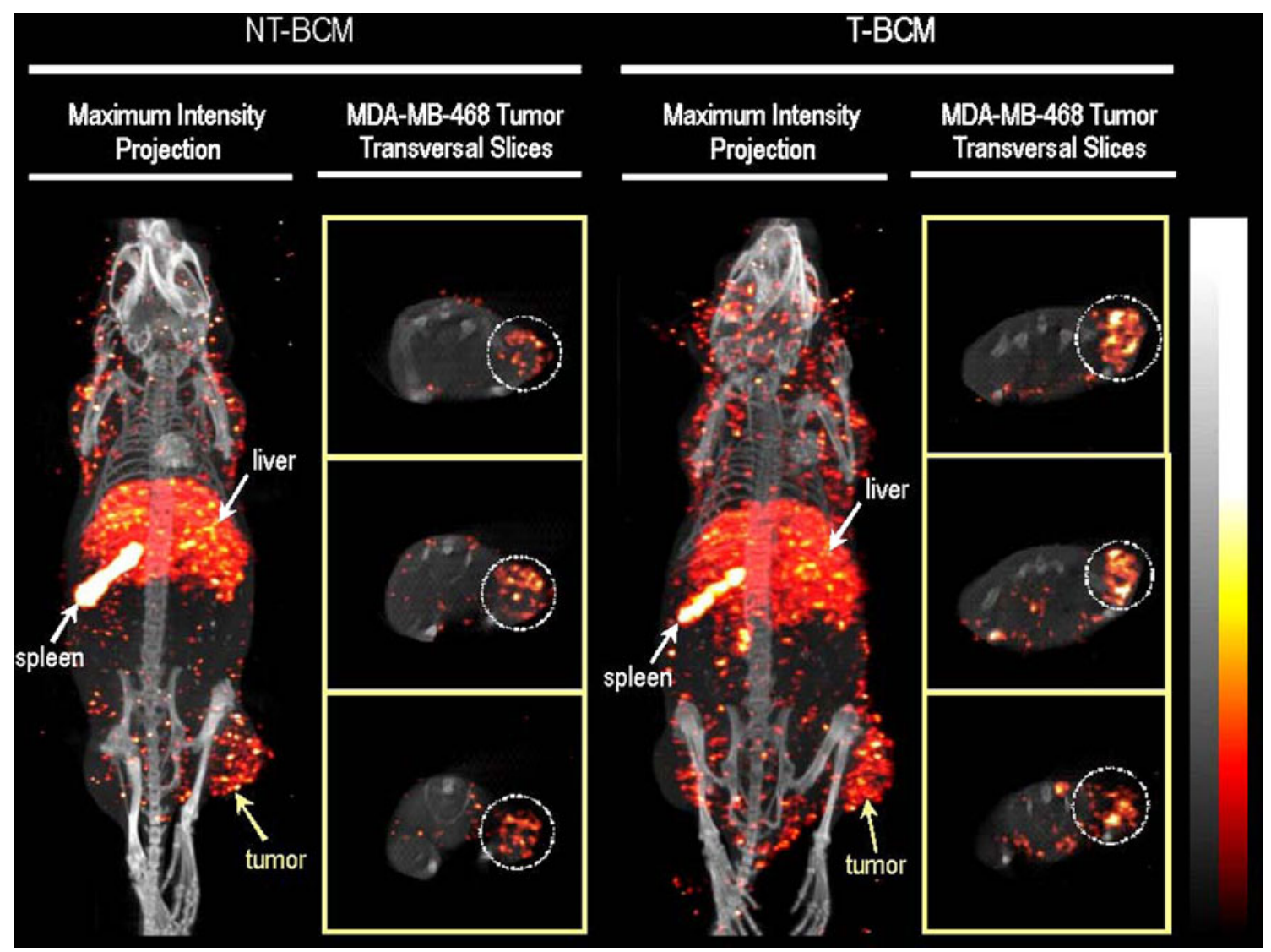

Fig. 6 MicroSPECT/CT images illustrating the whole-body biodistribution of the non-targeted block copolymer micelles (NT-BCM) and targeted block copolymer micelles (T-BCM) labeled with ${ }^{111}$ In, in MDA-MB-468 tumor-bearing mice that were injected intravenously at a dose of $250 \mathrm{mg} / \mathrm{kg}$ of PEG-b$\mathrm{PCL}$ copolymer. The maximum intensity projection and the tumor transverse slice images were acquired at $48 \mathrm{~h}$ post injection. The tumor transverse slices shown represent consecutive sections of the tumor at an approximate thickness of $4 \mathrm{~mm} / \mathrm{section}$ (77). Reproduced with permission from Elsevier. 
$\mathcal{T}_{2}$ relaxivity for ultrasensitive $\mathrm{MR}$ detection and cell cytotoxicity in $\alpha_{v} \beta_{6}$-expressing lung cancer cells were shown. Previously, the same micelles were conjugated with a cRGD ligand that can target $\alpha_{v} \beta_{3}$ integrins on tumor endothelial (SLK) cells (189), resulting in ultrasensitive detection by MRI and growth inhibition of tumor SLK cells. Hong et al. prepared a micellar formulation consisting of folate-conjugated PEG- $b$-PCL loaded with doxorubicin and SPIONs. In vitro studies with human hepatic carcinoma cells (Bel 7402 cells, which overexpress surface receptors for folic acid) showed a significant inhibition in proliferation compared to non-targeted micelles (190). Moreover, MR imaging revealed detection of the targeted micelles in the cells. These studies indicated the advantages of image-guided drug delivery. Diagnostics are considerably improved and drug delivery efficiency is significantly enhanced by the combination of active tumor targeting and imaging. Table VII summarizes the micellar formulation characteristics combining different approaches.

Despite the promising results in multifunctional micellar drug delivery research, the combination of all three features has not been investigated yet. Upcoming research should be focused on the development of even more advanced micellar systems to improve their efficacy. The aim is to get the highest drug concentration to the tumor tissue as possible which can be monitored by imaging to verify the absolute released drug concentration at the target site. This will result in personalized systems which are guided by multimodality imaging techniques.

\section{CONCLUSIONS AND FUTURE PERSPECTIVES}

A multitude of preclinical studies on multifunctional micelles has been published, which showed that micellebased drug delivery is advantageous over free drug delivery in laboratory animals, resulting in less adverse effects and toxicity in non-targeted areas. Until now, five (passively targeted) micelle products for anticancer therapy have been investigated in clinical trials, of which one has been granted FDA-approval (Genexol-PM) to be used in patients with breast cancer.

To fully exploit the clinical possibilities of this new generation of nanomedicines, further development is required regarding drug loading and retention, circulation kinetics, tumor accumulation, target cell uptake and intracellular drug release. Additionally, the combination of multiple mechanisms for micelle-based drug delivery in anticancer therapy, characterized by active targeting, imaging and triggered release offers challenging opportunities to improve therapeutic efficacy. Despite the interesting approaches for multifunctional drug-loaded micellar formulations, many opportunities have not been explored yet. Frequently used anticancer drugs like paclitaxel, cisplatin and 5-FU have to be investigated for multifunctional micelle-based anticancer therapy. Moreover, no multifunctional micelles based on light- or ultrasound-triggered release have been prepared yet, and only a few multifunctional micelle formulations which are able to release their content after being exposed to mild hyperthermia have been evaluated. Since imaging is an important tool to investigate biodistribution and release profiles, imaging agents should be included in the new generation of multifunctional micelles. The next step is to implement these micellar formulations in clinical anticancer therapies. Therefore, it is important that the micellar formulations comply with the pharmacopeia and that preparation of the micelles can be performed under GMP conditions. Clinical studies require multidisciplinary expertise at different levels in which a close corporation between researchers and clinicians is essential.

Labeling of micelles with a radioactive tracer allows tracking of the administered dose. For that reason, it is not

Table VII Multifunctional Micellar Formulations

\begin{tabular}{|c|c|c|c|c|c|}
\hline Block copolymer & Targeting ligand & Imaging agent & Trigger & Drug & Ref. \\
\hline PEG-b-PBLA & folate & $\mathrm{n} / \mathrm{a}$ & $\mathrm{pH}$ & Dox & $(|80| 8 \mid)$, \\
\hline poly(L-histidine)-b-PEG-b-PLLA & folate & $\mathrm{n} / \mathrm{a}$ & $\mathrm{pH}$ & Dox & $(182)$ \\
\hline poly(L-histidine)-b-PEG-b-PLLA & TAT & $\mathrm{n} / \mathrm{a}$ & $\mathrm{pH}$ & Dox & $(101,183,184)$ \\
\hline PEG-b-PMA-co-PCL & folate & $\mathrm{n} / \mathrm{a}$ & $\mathrm{pH}$ & Dox & $(185)$ \\
\hline PEG-b-PDLLA & CRKRLDRN & $\mathrm{n} / \mathrm{a}$ & $\mathrm{pH}$ & Dox & $(186)$ \\
\hline PEG-b-PAA-b-PMA & folate & ${ }^{64} \mathrm{Cu}$ (autoradiography) & $\mathrm{n} / \mathrm{a}$ & $\mathrm{n} / \mathrm{a}$ & $(187)$ \\
\hline PEG-b-PCL & EGF & 111 In (SPECT/CT) & $\mathrm{n} / \mathrm{a}$ & $\mathrm{n} / \mathrm{a}$ & $(77)$ \\
\hline PEG-b-PDLLA & LCP & SPIO (MRI) & $\mathrm{n} / \mathrm{a}$ & Dox & $(188)$ \\
\hline PEG-b-PDLLA & cRGD & SPIO (MRI) & $\mathrm{n} / \mathrm{a}$ & Dox & $(189)$ \\
\hline PEG-b-PCL & folate & SPIO (MRI) & $\mathrm{n} / \mathrm{a}$ & Dox & $(190)$ \\
\hline
\end{tabular}

PBLA poly( $(\beta$-benzyl-L-aspartate); n/a not applicable; TAT trans-acting activator of transcription; PCL poly( $\varepsilon$-caprolactone); PMA poly(malic acid); PAA-b-PMA poly(acrylic acid-b-methyl acrylate); LCP lung cancer-targeting peptide. 
only an attractive tool for in vivo biodistribution studies, but it can also be exploited as theranostics in patient treatment to develop individual-based therapy. Dosimetry can be used to adjust the dose to the patient since the amount of radioactivity in the tumor tissue then correlates linearly with the local drug concentration, provided that both drug and contrast agent are stably associated in the micelle during circulation. A scout dose can be administered to the patient to investigate the tumor-to-non-tumor ratio, and depending on factors like tumor type, size and responsiveness, an optimal treatment dose can be calculated.

Next to conventional MRI and nuclear imaging, also the chemical exchange saturation transfer (CEST) modality can be exploited for imaging purposes in micelle-based drug delivery. The CEST modality is a recently introduced MRderived imaging procedure which is based on the use of CEST agents containing one or more exchangeable proton pools $(191,192)$. Radiofrequency irradiation of the resonance of the mobile protons results in a saturated magnetization. Due to chemical exchange, the saturated magnetization is transferred to the water signal. The major advantage of CEST agents over conventional MRI is that the signal can be generated locally. Once CEST agents are encapsulated into micelles, the coating will initially prevent signal enhancement, but after release the contrast agents will come into contact with their surroundings and exchange protons with the bulk water protons, which reduces the signal intensity, resulting in negative contrast (193). At this moment, no micelle-based CEST agents have been developed, but the hopeful prospect will certainly lead to the exploration of this research area.

The versatility of micelle-based drug delivery and the large number of promising preclinical studies describing numerous approaches to optimize these nanomedicines will bring the development of a 'magic bullet' a major step forward. Now it is time to bring this potential into clinical practice.

\section{ACKNOWLEDGEMENTS}

The authors would like to thank Dr. Cristianne Rijcken from the Department of Pharmaceutics, Utrecht Institute for Pharmaceutical Sciences (UIPS), Utrecht University, The Netherlands, for valuable discussions. The authors would like to acknowledge Meditrans (an Integrated Project funded by the European Commission) for the financial support.

Open Access This article is distributed under the terms of the Creative Commons Attribution Noncommercial License which permits any noncommercial use, distribution, and reproduction in any medium, provided the original author(s) and source are credited.

\section{REFERENCES}

1. World Health Organization: fact sheet cancer. http://www.who.int/ mediacentre/factsheets/fs297/en/index.html. (accessed 10-12-09).

2. Ferlay J, Parkin DM, Steliarova-Foucher E. Estimates of cancer incidence and mortality in Europe in 2008. Eur J Cancer. 2010;46:765-81.

3. Torchilin VP. Micellar nanocarriers: pharmaceutical perspectives. Pharm Res. 2007;24:1-16.

4. Torchilin VP. Targeted pharmaceutical nanocarriers for cancer therapy and Imaging. AAPS J. 2007;9:E128-47.

5. Mishra B, Patel BB, Tiwari S. Colloidal nanocarriers: a review on formulation technology, types and applications toward targeted drug delivery. Nanomedicine. 2010;6:9-24.

6. Matsumura Y. Poly (amino acid) micelle nanocarriers in preclinical and clinical studies. Adv Drug Deliv Rev. 2008;60:899-914.

7. Maeda H, Wu J, Sawa T, Matsumura Y, Hori K. Tumor vascular permeability and the EPR effect in macromolecular therapeutics: a review. J Control Release. 2000;65:271-84.

8. Weiss RB, Donehower RC, Wiernik PH, Ohnuma T, Gralla RJ, Trump DL, et al. Hypersensitivity reactions from taxol. J Clin Oncol. 1990;8:1263-8.

9. Kloover JS. M.A.den Bakker, H. Gelderblom, and J.P.van Meerbeeck. Fatal outcome of a hypersensitivity reaction to paclitaxel: a critical review of premedication regimens. Br J Cancer. 2004;90:304-5.

10. Rijcken CJ, Soga O, Hennink WE. and C.F.van Nostrum. Triggered destabilisation of polymeric micelles and vesicles by changing polymers polarity: an attractive tool for drug delivery. J Control Release. 2007;120:131-48.

11. Jones MC, Leroux JC. Polymeric micelles - a new generation of colloidal drug carriers. Eur J Pharm Biopharm. 1999;48:10111.

12. Adams ML, Lavasanifar A, Kwon GS. Amphiphilic block copolymers for drug delivery. J Pharm Sci. 2003;92:1343-55.

13. Trubetskoy VS. Polymeric micelles as carriers of diagnostic agents. Adv Drug Deliv Rev. 1999;37:81-8.

14. Torchilin VP. Structure and design of polymeric surfactantbased drug delivery systems. J Control Release. 2001;73:137-72.

15. Sutton D, Nasongkla N, Blanco E, Gao J. Functionalized micellar systems for cancer targeted drug delivery. Pharm Res. 2007;24:1029-46.

16. Patel S, Lavasanifar A, Choi P. Application of molecular dynamics simulation to predict the compatability between water-insoluble drugs and self-associating poly(ethylene oxide)b-poly(epsilon-caprolactone) block copolymers. Biomacromolecules. 2008;9:3014-23.

17. Gaucher G, Dufresne MH, Sant VP, Kang N, Maysinger D, Leroux JC. Block copolymer micelles: preparation, characterization and application in drug delivery. J Control Release. 2005; 109:169-88.

18. Blanco E, Kessinger CW, Sumer BD, Gao J. Multifunctional micellar nanomedicine for cancer therapy. Exp Biol Med (Maywood). 2009;234:123-31.

19. Kabanov AV, Batrakova EV, Alakhov VY. Pluronic block copolymers as novel polymer therapeutics for drug and gene delivery. J Control Release. 2002;82:189-212.

20. Carstens MG, van Nostrum CF, Ramzi A, Meeldijk JD, Verrijk $\mathrm{R}$, de Leede LL, et al. Poly(ethylene glycol)-oligolactates with monodisperse hydrophobic blocks: preparation, characterization, and behavior in water. Langmuir. 2005;21:11446-54.

21. Carstens MG, de Jong PH, van Nostrum CF, Kemmink J, Verrijk R, de Leede LG, et al. The effect of core composition in biodegradable oligomeric micelles as taxane formulations. Eur J Pharm Biopharm. 2008;68:596-606. 
22. Matsumura Y, Kataoka K. Preclinical and clinical studies of anticancer agent-incorporating polymer micelles. Cancer Sci. 2009; 100:572-9.

23. United States National Library of Medicine, overview of clinical trials available via www.clinicaltrials.org. (accessed 01-27-10).

24. Hamaguchi T, Kato K, Yasui H, Morizane C, Ikeda M, Ueno $\mathrm{H}$, et al. A phase I and pharmacokinetic study of NK105, a paclitaxel-incorporating micellar nanoparticle formulation. Br J Cancer. 2007;97:170-6.

25. Supratek Pharm Inc. Pipepline available via www.supratek.com. (accessed 10-12-09)

26. Matsumura Y. Polymeric micellar delivery systems in oncology. Jpn J Clin Oncol. 2008;38:793-802.

27. Wilson RH, Plummer R, Adam J, Eatock M, Boddy AV, Griffin $\mathrm{M}$, et al. Phase I and pharmacokinetic study of NC-6004, a new platinum entity of cisplatin-conjugated polymer forming micelles. J Clin Oncol. 26: 2008 (May 20 suppl; abstr 2573).

28. Kim TY, Kim DW, Chung JY, Shin SG, Kim SC, Heo DS, et al. Phase I and pharmacokinetic study of Genexol-PM, a cremophor-free, polymeric micelle-formulated paclitaxel, in patients with advanced malignancies. Clin Cancer Res. 2004;10:3708-16.

29. Lee KS, Chung HC, Im SA, Park YH, Kim CS, Kim SB, et al. Multicenter phase II trial of Genexol-PM, a Cremophor-free, polymeric micelle formulation of paclitaxel, in patients with metastatic breast cancer. Breast Cancer Res Treat. 2008;108:241-50.

30. Podoltsev NA, Rubin M, Figueroa J, Lee MY, Kwonj J, Yu J, et al. Phase II clinical trial of paclitaxel loaded polymeric micelle (GPM) in patients (pts) with advanced pancreatic cancer (APC): J Clin Oncol. 26: 2008 (May 20 suppl; abstr 4627).

31. Saif MW, Rubin M, Figueroa J, Kerr RO. Multicenter phase II trial of Genexol-PM (GPM), a novel Cremophor-free, polymeric micelle formulation of paclitaxel in patients with advanced pancreatic cancer (APC): Final results. Gastrointestinal Cancers Symposium 2008.

32. Kim DW, Kim SY, Kim HK, Kim SW, Shin SW, Kim JS, et al. Multicenter phase II trial of Genexol-PM, a novel Cremophorfree, polymeric micelle formulation of paclitaxel, with cisplatin in patients with advanced non-small-cell lung cancer. Ann Oncol. 2007;18:2009-14.

33. Koizumi F, Kitagawa M, Negishi T, Onda T, Matsumoto S, Hamaguchi $\mathrm{T}$, et al. Novel SN-38-incorporating polymeric micelles, NK012, eradicate vascular endothelial growth factorsecreting bulky tumors. Cancer Res. 2006;66:10048-56.

34. Saito Y, Yasunaga M, Kuroda J, Koga Y, Matsumura Y. Enhanced distribution of NK012, a polymeric micelle-encapsulated SN-38, and sustained release of $\mathrm{SN}-38$ within tumors can beat a hypovascular tumor. Cancer Sci. 2008;99:1258-64.

35. Nakajima TE, Yasunaga M, Kano Y, Koizumi F, Kato K, Hamaguchi $\mathrm{T}$, et al. Synergistic antitumor activity of the novel SN-38-incorporating polymeric micelles, NK012, combined with 5 -fluorouracil in a mouse model of colorectal cancer, as compared with that of irinotecan plus 5-fluorouracil. Int J Cancer. 2008;122:2148-53.

36. Burris HA, Infante JR, Spigel DR, Greco FA, Thompson DS, Matsumoto S, et al. A phase I dose-escalation study of NK012. J Clin Oncol. 26: 2008 (May 20 suppl; abstr 2538).

37. Kato K, Hamaguchi T, Shirao K, Shimada Y, Doi T, Ohtsu A, et al. Interim analysis of phase I study of NK012, polymer micelle SN-38, in patients with advanced cancer. Gastrointestinal Cancers Symposium 2008.

38. Khayat D, Antoine EC, Coeffic D. Taxol in the management of cancers of the breast and the ovary. Cancer Invest. 2000;18:24260.

39. Carney DN. Chemotherapy in the management of patients with inoperable non-small cell lung cancer. Semin Oncol. 1996;23:71-5.
40. Rowinsky EK, Donehower RC. Paclitaxel (taxol). N Engl J Med. 1995;332:1004-14.

41. Hamaguchi T, Matsumura Y, Suzuki M, Shimizu K, Goda R, Nakamura I, et al. NK105, a paclitaxel-incorporating micellar nanoparticle formulation, can extend in vivo antitumour activity and reduce the neurotoxicity of paclitaxel. $\mathrm{Br} \mathrm{J}$ Cancer. 2005;92:1240-6.

42. Danson S, Ferry D, Alakhov V, Margison J, Kerr D, Jowle D, et al. Phase I dose escalation and pharmacokinetic study of pluronic polymer-bound doxorubicin (SP1049G) in patients with advanced cancer. Br J Cancer. 2004;90:2085-91.

43. Venne A, Li S, Mandeville R, Kabanov A, Alakhov V. Hypersensitizing effect of pluronic L61 on cytotoxic activity, transport, and subcellular distribution of doxorubicin in multiple drug-resistant cells. Cancer Res. 1996;56:3626-9.

44. Batrakova EV, Dorodnych TY, Klinskii EY, Kliushnenkova EN, Shemchukova OB, Goncharova ON, et al. Anthracycline antibiotics non-covalently incorporated into the block copolymer micelles: in vivo evaluation of anti-cancer activity. $\mathrm{Br} \mathrm{J}$ Cancer. 1996;74:1545-52.

45. Alakhov V, Klinski E, Li SM, Pietrzynski G, Venne A, Batrakova $\mathrm{E}$, et al. Block copolymer-based formulation of doxorubicin. From cell screen to clinical trials. Colloids Surf B-Biointerfaces. 1999;16:113-34.

46. Armstrong A, Brewer J, Newman C, Alakhov V, Pietrzynski G, Campbell S, et al. SP1049C as first-line therapy in advanced (inoperable or metastatic) adenocarcinoma of the oesophagus: A phase II window study. J Clin Oncol. 24: 2006 (June 20 suppl; abstr. 4080).

47. Valle JW, Lawrence J, Brewer J, Clayton A, Corrie P, Alakhov V, et al. A phase II, window study of SP1049C as first-line therapy in inoperable metastatic adenocarcinoma of the oesophagus. J Clin Oncol. 22: 2004 (July 15 suppl; abstr. 4195).

48. Nishiyama N, Okazaki S, Cabral H, Miyamoto M, Kato Y, Sugiyama $\mathrm{Y}$, et al. Novel cisplatin-incorporated polymeric micelles can eradicate solid tumors in mice. Cancer Res. 2003;63:8977-83.

49. Uchino H, Matsumura Y, Negishi T, Koizumi F, Hayashi T, Honda $\mathrm{T}$, et al. Cisplatin-incorporating polymeric micelles (NC6004) can reduce nephrotoxicity and neurotoxicity of cisplatin in rats. Br J Cancer. 2005;93:678-87.

50. Kim SC, Kim DW, Shim YH, Bang JS, Oh HS, Wan KS, et al. In vivo evaluation of polymeric micellar paclitaxel formulation: toxicity and efficacy. J Control Release. 2001;72:191-202.

51. Tan E, Leong SS, Lim WT, Toh CK, Chowbay B. Weekly administration of a cremophor-free, polymeric micelle formulation of paclitaxel to Asian patients with advanced solid tumor: Phase I study results. Gastrointestinal Cancers Symposium 2007.

52. Kim C, Bae S, Lee N, Lee K, Park S, Kim D, et al. Phase II study of Genexol (paclitaxel) and carboplatin as first-line treatment of advanced or metastatic non-small-cell lung cancer (NSCLC). J Clin Oncol. 24: 2006 (June 20 suppl.; abstr. 17049).

53. Mahmud A, Xiong XB, Aliabadi HM, Lavasanifar A. Polymeric micelles for drug targeting. J Drug Target. 2007;15:553-84.

54. Torchilin VP. Gell penetrating peptide-modified pharmaceutical nanocarriers for intracellular drug and gene delivery. Biopolymers. 2008;90:604-10.

55. Kabanov AV, Chekhonin VP, Alakhov VY, Batrakova EV, Lebedev AS, Melik-Nubarov NS, et al. The neuroleptic activity of haloperidol increases after its solubilization in surfactant micelles. Micelles as microcontainers for drug targeting. FEBS Lett. 1989;258:343-5.

56. Vega J, Ke S, Fan Z, Wallace S, Charsangavej C, Li C. Targeting doxorubicin to epidermal growth factor receptors by site-specific conjugation of C225 to poly(L-glutamic acid) through a polyethylene glycol spacer. Pharm Res. 2003;20: 826-32. 
57. Wen X, Wu QP, Ke S, Ellis L, Charnsangavej C, Delpassand AS, et al. Conjugation with (111)In-DTPA-poly(ethylene glycol) improves imaging of anti-EGF receptor antibody C225. J Nucl Med. 2001;42:1530-7.

58. Mendelsohn J. Epidermal growth factor receptor inhibition by a monoclonal antibody as anticancer therapy. Clin Cancer Res. 1997;3:2703-7.

59. Leamon CP, Reddy JA. Folate-targeted chemotherapy. Adv Drug Deliv Rev. 2004;56:1127-41.

60. Lu Y, Low PS. Immunotherapy of folate receptor-expressing tumors: review of recent advances and future prospects. J Control Release. 2003;91:17-29.

61. Avraamides CJ, Garmy-Susini B, Varner JA. Integrins in angiogenesis and lymphangiogenesis. Nat Rev Cancer. 2008;8:604-17.

62. Greish K. Enhanced permeability and retention of macromolecular drugs in solid tumors: a royal gate for targeted anticancer nanomedicines. J Drug Target. 2007;15:457-64.

63. Nasongkla N, Shuai X, Ai H, Weinberg BD, Pink J, Boothman DA, et al. cRGD-functionalized polymer micelles for targeted doxorubicin delivery. Angew Chem Int Ed Engl. 2004;43:6323-7.

64. Torchilin VP, Lukyanov AN, Gao Z, Papahadjopoulos-Sternberg B. Immunomicelles: targeted pharmaceutical carriers for poorly soluble drugs. Proc Natl Acad Sci USA. 2003;100:6039-44.

65. Yoo HS, Park TG. Folate receptor targeted biodegradable polymeric doxorubicin micelles. J Control Release. 2004;96:273-83.

66. Park EK, Lee SB, Lee YM. Preparation and characterization of methoxy poly(ethylene glycol)/poly(epsilon-caprolactone) amphiphilic block copolymeric nanospheres for tumor-specific folatemediated targeting of anticancer drugs. Biomaterials. 2005;26:1053-61.

67. Han X, Liu J, Liu M, Xie C, Zhan C, Gu B, et al. 9-NC-loaded folate-conjugated polymer micelles as tumor targeted drug delivery system: preparation and evaluation in vitro. Int J Pharm. 2009;372:125-31.

68. Wang Y, Yu L, Han L, Sha X, Fang X. Difunctional Pluronic copolymer micelles for paclitaxel delivery: synergistic effect of folatemediated targeting and Pluronic-mediated overcoming multidrug resistance in tumor cell lines. Int J Pharm. 2007;337:63-73.

69. Onyuksel H, Mohanty PS, Rubinstein I. VIP-grafted sterically stabilized phospholipid nanomicellar 17-allylamino-17-demethoxy geldanamycin: a novel targeted nanomedicine for breast cancer. Int J Pharm. 2009;365:157-61.

70. Torchilin VP. PEG-based micelles as carriers of contrast agents for different imaging modalities. Adv Drug Deliv Rev. 2002;54:235-52

71. Nijsen JF, Krijger GC. and A.D.van het Schip. The bright future of radionuclides for cancer therapy. Anticancer Agents Med Chem. 2007:7:271-90.

72. Fossheim S, Johansson C, Fahlvik AK, Grace D, Klaveness J. Lanthanide-based susceptibility contrast agents: assessment of the magnetic properties. Magn Reson Med. 1996;35:201-6.

73. Seevinck PR, Seppenwoolde JH, de Wit TC, Nijsen JF, Beekman FJ, van het Schip AD. Factors affecting the sensitivity and detection limits of MRI, CT, and SPECT for multimodal diagnostic and therapeutic agents. Anticancer Agents Med Chem. 2007;7:317-34.

74. Janjic JM, Ahrens ET. Fluorine-containing nanoemulsions for MRI cell tracking. Wiley Interdiscip Rev Nanomed Nanobiotechnol. 2009; 1:492-501.

75. Zielhuis SW, Nijsen JFW, Seppenwoolde JH, Zonnenberg BA, Bakker CJG, Hennink WE, et al. Lanthanide bearing microparticulate systems for multi-modality imaging and targeted therapy of cancer. Curr Med Chem Anti -Canc Agents. $2005 \cdot 5 \cdot 303-13$.

76. Coenegrachts K, De Greeter F, ter Beek L, Walgraeve N, Bipat $\mathrm{S}$, Stoker J, et al. Comparison of MRI (including SS SE-EPI and
SPIO-enhanced MRI) and FDG-PET/CT for the detection of colorectal liver metastases. Eur Radiol. 2009;19:370-9.

77. Lee H, Hoang B, Fonge H, Reilly RM, Allen C. In vivo distribution of polymeric nanoparticles at the whole-body, tumor, and cellular levels. Pharm Res (2010).

78. Hoang B, Lee H, Reilly RM, Allen C. Noninvasive monitoring of the fate of $111 \mathrm{In}$-labeled block copolymer micelles by high resolution and high sensitivity microSPECT/CT imaging. Mol Pharm. 2009;6:581-92.

79. Shokeen M, Fettig NM, Rossin R. Synthesis, in vitro and in vivo evaluation of radiolabeled nanoparticles. Q J Nucl Med Mol Imaging. 2008;52:267-77.

80. Visentin R, Pasut G, Veronese FM, Mazzi U. Highly efficient technetium-99 m labeling procedure based on the conjugation of $\mathrm{N}$-[N-(3-diphenylphosphinopropionyl)glycyl]cysteine ligand with poly(ethylene glycol). Bioconjug Chem. 2004;15:1046-54.

81. Pressly ED, Rossin R, Hagooly A, Fukukawa K, Messmore BW, Welch MJ, et al. Structural effects on the biodistribution and positron emission tomography (PET) imaging of well-defined (64) Cu-labeled nanoparticles comprised of amphiphilic block graft copolymers. Biomacromolecules. 2007;8:3126-34.

82. Fukukawa K, Rossin R, Hagooly A, Pressly ED, Hunt JN, Messmore BW, et al. Synthesis and characterization of core-shell star copolymers for in vivo PET imaging applications. Biomacromolecules. 2008;9:1329-39.

83. Shiraishi K, Kawano K, Minowa T, Maitani Y, Yokoyama M. Preparation and in vivo imaging of PEG-poly(L-lysine)-based polymeric micelle MRI contrast agents. J Control Release. 2009;136:14-20.

84. Talelli M, Rijcken CJ, Lammers T, Seevinck PR, Storm G, van Nostrum CF, et al. Superparamagnetic iron oxide nanoparticles encapsulated in biodegradable thermosensitive polymeric micelles: toward a targeted nanomedicine suitable for image-guided drug delivery. Langmuir. 2009;25:2060-7.

85. Khemtong C, Kessinger CW, Togao O, Ren J, Takahashi M, Sherry AD, et al. Off-resonance saturation magnetic resonance imaging of superparamagnetic polymeric micelles. Conf Proc IEEE Eng Med Biol Soc. 2009;2009:4095-7.

86. Lu J, Ma S, Sun J, Xia C, Liu C, Wang Z, et al. Manganese ferrite nanoparticle micellar nanocomposites as MRI contrast agent for liver imaging. Biomaterials. 2009;30:2919-28.

87. Lanza GM, Winter PM, Neubauer AM, Caruthers SD, Hockett FD, Wickline SA. $1 \mathrm{H} / 19 \mathrm{~F}$ magnetic resonance molecular imaging with perfluorocarbon nanoparticles. Curr Top Dev Biol. 2005;70:57-76.

88. Caruthers SD, Neubauer AM, Hockett FD, Lamerichs R, Winter PM, Scott MJ, et al. In vitro demonstration using $19 \mathrm{~F}$ magnetic resonance to augment molecular imaging with paramagnetic perfluorocarbon nanoparticles at 1.5 Tesla. Invest Radiol. 2006;41:305-12.

89. Soman NR, Lanza GM, Heuser JM, Schlesinger PH, Wickline SA. Synthesis and characterization of stable fluorocarbon nanostructures as drug delivery vehicles for cytolytic peptides. Nano Lett. 2008;8:1131-6.

90. Peng H, Blakey I, Dargaville B, Rasoul F, Rose S, Whittaker AK. Synthesis and evaluation of partly fluorinated block copolymers as MRI imaging agents. Biomacromolecules. 2009;10:374-81.

91. Du W, Nystrom AM, Zhang L, Powell KT, Li Y, Cheng C, et al. Amphiphilic hyperbranched fluoropolymers as nanoscopic 19F magnetic resonance imaging agent assemblies. Biomacromolecules. 2008;9:2826-33.

92. Torchilin VP, Frank-Kamenetsky MD, Wolf GL. CT visualization of blood pool in rats by using long-circulating, iodine-containing micelles. Acad Radiol. 1999;6:61-5.

93. Kwon GS, Okano T. Polymeric micelles as new drug carriers. Adv Drug Deliv Rev. 1996;21:107-16. 
94. Teng Y, Morrison ME, Munk P, Webber SE, Prochazka K. Release kinetics studies of aromatic molecules into water from block polymer micelles. Macromolecules. 1998;31:3578-87.

95. Rapoport N. Physical stimuli-responsive polymeric micelles for anticancer drug delivery. Prog Polym Sci. 2007;32:962-90.

96. Chen W, Meng F, Li F, Ji SJ, Zhong Z. pH-responsive biodegradable micelles based on acid-labile polycarbonate hydrophobe: synthesis and triggered drug release. Biomacromolecules (2009).

97. Engin K, Leeper DB, Cater JR, Thistlethwaite AJ, Tupchong L, McFarlane JD. Extracellular pH distribution in human tumours. Int J Hyperthermia. 1995;11:211-6.

98. Lee ES, Gao Z, Bae YH. Recent progress in tumor $\mathrm{pH}$ targeting nanotechnology. J Control Release. 2008;132:164-70.

99. Stubbs M, McSheehy PM, Griffiths JR, Bashford CL. Causes and consequences of tumour acidity and implications for treatment. Mol Med Today. 2000;6:15-9.

100. Lee ES, Gao Z, Bae YH. Recent progress in tumor $\mathrm{pH}$ targeting nanotechnology. J Control Release. 2008;132:164-70.

101. Lee ES, Na K, Bae YH. Super $\mathrm{pH}$-sensitive multifunctional polymeric micelle. Nano Lett. 2005;5:325-9.

102. Yin H, Bae YH. Physicochemical aspects of doxorubicin-loaded $\mathrm{pH}$-sensitive polymeric micelle formulations from a mixture of poly(L-histidine)-b-poly(L-lactide)-b-poly(ethylene glycol). Eur J Pharm Biopharm. 2009;71:223-30.

103. Yin H, Lee ES, Kim D, Lee KH, Oh KT, Bae YH. Physicochemical characteristics of $\mathrm{pH}$-sensitive poly(L-histidine)-b-poly(ethylene glycol)/poly(L-lactide)-b-poly(ethylene glycol) mixed micelles. J Control Release. 2008;126:130-8.

104. Kim D, Lee ES, Park K, Kwon IC, Bae YH. Doxorubicin loaded $\mathrm{pH}$-sensitive micelle: antitumoral efficacy against ovarian A2780/DOXR tumor. Pharm Res. 2008;25:2074-82.

105. Lee ES, Shin HJ, Na K, Bae YH. Poly(L-histidine)-PEG block copolymer micelles and $\mathrm{pH}$-induced destabilization. J Control Release. 2003;90:363-74.

106. Lee ES, Na K, Bae YH. Doxorubicin loaded pH-sensitive polymeric micelles for reversal of resistant MCF-7 tumor. J Control Release. 2005; 103:405-18.

107. Lee ES, Oh KT, Kim D, Youn YS, Bae YH. Tumor pH-responsive flower-like micelles of poly(L-lactic acid)-b-poly(ethylene glycol)-bpoly(L-histidine). J Control Release. 2007;123:19-26.

108. Borchert U, Lipprandt U, Bilang M, Kimpfler A, Rank A, Peschka-Suss R, et al. pH-induced release from P2VP-PEO block copolymer vesicles. Langmuir. 2006;22:5843-7.

109. Karanikolas A, Tsolakis P, Bokias G, Tsitsilianis C. Stimuliresponsive poly(ethylene oxide)-b-poly(2-vinylpyridine)-b-poly (ethylene oxide) triblock copolymers and complexation with poly(acrylic acid) at low p H. Eur Phys J E Soft Matter (2008).

110. Filippov S, Hruby M, Konak C, Mackova H, Spirkova M, Stepanek P. Novel pH-responsive nanoparticles. Langmuir. 2008;24:9295-301.

111. Du FS, Huang XN, Chen GT, Lin SS, Liang DH, Li ZC. Aqueous solution properties of the acid-labile thermoresponsive poly(meth)acrylamides with pendent cyclic orthoester groups. Macromolecules. 2010;43:2474-83.

112. Gillies ER, Frechet JMJ. Development of acid-sensitive copolymer micelles for drug delivery. Pure Appl Chem. 2004;76:1295-307.

113. Tang RP, Ji WH, Wang C. Amphiphilic block copolymers bearing ortho ester side-chains: $\mathrm{pH}$-dependent hydrolysis and self-assembly in water. Macromol Biosci. 2010;10:192-201.

114. Bae Y, Nishiyama N, Fukushima S, Koyama H, Yasuhiro M, Kataoka K. Preparation and biological characterization of polymeric micelle drug carriers with intracellular $\mathrm{pH}$-triggered drug release property: tumor permeability, controlled subcellular drug distribution, and enhanced in vivo antitumor efficacy. Bioconjug Chem. 2005;16:122-30.
115. Huang XN, Du FS, Cheng J, Dong YQ Liang DH, Ji SP, et al. Acid-sensitive polymeric micelles based on thermoresponsive block copolymers with pendent cyclic orthoester groups. Macromolecules. 2009;42:783-90.

116. Pelton R. Temperature-sensitive aqueous microgels. Adv Colloid Interface Sci. 2000;85:1-33.

117. Schild HG. Poly (N-Isopropylacrylamide) — experiment, theory and application. Prog Polym Sci. 1992;17:163-249.

118. Topp MDC, Dijkstra PJ, Talsma H, Feijen J. Thermosensitive micelle-forming block copolymers of poly(ethylene glycol) and poly(N-isopropylacrylamide). Macromolecules. 1997;30:851820.

119. Wei H, Cheng SX, Zhang XZ, Zhuo RX. Thermo-sensitive polymeric micelles based on poly(N-isopropylacrylamide) as drug carriers. Prog Polym Sci. 2009;34:893-910.

120. Chung JE, Yokoyama M, Okano T. Inner core segment design for drug delivery control of thermo-responsive polymeric micelles. J Control Release. 2000;65:93-103.

121. Chung JE, Yokoyama M, Yamato M, Aoyagi T, Sakurai Y, Okano T. Thermo-responsive drug delivery from polymeric micelles constructed using block copolymers of poly $(\mathrm{N}$ isopropylacrylamide) and poly(butylmethacrylate). J Control Release. 1999;62:115-27.

122. Kohori F, Sakai K, Aoyagi T, Yokoyama M, Yamato M, Sakurai T. Control of adriamycin cytotoxic activity using thermally responsive polymeric micelles composed of poly $(\mathrm{N}-$ isopropylacrylamide-co-N, N-dimethylacrylamide)-b-poly(D, Llactide). Colloids Surf B Biointerfaces. 1999;16:195-205.

123. Liu SQ Tong YW, Yang YY. Thermally sensitive micelles selfassembled from poly(N-isopropylacrylamide-co-N, Ndimethylacrylamide)-b-poly( $\mathrm{D}$, L-lactide-c o-glycolide) for controlled delivery of paclitaxel. Mol Biosyst. 2005;1:158-65.

124. Liu SQ, Tong YW, Yang YY. Incorporation and in vitro release of doxorubicin in thermally sensitive micelles made from poly $(\mathrm{N}$ isopropylacrylamide-co-N, N-dimethylacrylamide)-b-poly(D, Llactide-c o-glycolide) with varying compositions. Biomaterials. 2005;26:5064-74

125. Liu B, Yang M, Li R, Ding Y, Qian X, Yu L, et al. The antitumor effect of novel docetaxel-loaded thermosensitive micelles. Eur J Pharm Biopharm. 2008;69:527-34.

126. Qu T, Wang A, Yuan J, Shi J, Gao Q. Preparation and characterization of thermo-responsive amphiphilic triblock copolymer and its self-assembled micelle for controlled drug release. Colloids Surf B Biointerfaces. 2009;72:94-100.

127. Nakayama M, Okano T, Miyazaki T, Kohori F, Sakai K, Yokoyama M. Molecular design of biodegradable polymeric micelles for temperature-responsive drug release. J Control Release. 2006;115:46-56.

128. Prabaharan M, Grailer JJ, Steeber DA, Gong S. Thermosensitive micelles based on folate-conjugated poly(N-vinylcaprolactam)block-poly(ethylene glycol) for tumor-targeted drug delivery. Macromol Biosci. 2009;9:744-53.

129. Talelli M, Rijcken CJF, van Nostrum CF, Storm G, Hennink WE. Micelles based on HPMA copolymers. Adv Drug Deliv Rev. 2010;62:231-9.

130. Soga O, van Nostrum CF, Hennink WE. Poly(N-(2-hydroxypropyl) methacrylamide mono/di lactate): a new class of biodegradable polymers with tuneable thermosensitivity. Biomacromolecules. 2004;5:818-21.

131. Soga O, van Nostrum GF, Ramzi A, Visser T, Soulimani F, Frederik PM, et al. Physicochemical characterization of degradable thermosensitive polymeric micelles. Langmuir. 2004;20:9388-95.

132. Soga O, van Nostrum CF, Fens M, Rijcken CJ, Schiffelers RM, Storm $\mathrm{G}$, et al. Thermosensitive and biodegradable polymeric micelles for paclitaxel delivery. J Control Release. 2005;103:34153. 
133. Opanasopit P, Yokoyama M, Watanabe M, Kawano K, Maitani $\mathrm{Y}$, Okano T. Influence of serum and albumins from different species on stability of camptothecin-loaded micelles. J Control Release. 2005;104:313-21.

134. Liu JB, Zeng FQ, Allen C. Influence of serum protein on polycarbonate-based copolymer micelles as a delivery system for a hydrophobic anti-cancer agent. J Control Release. 2005;103:48197.

135. Savic R, Azzam T, Eisenberg A, Maysinger D. Assessment of the integrity of poly(caprolactone)-b-poly(ethylene oxide) micelles under biological conditions: a fluorogenic-based approach. Langmuir. 2006;22:3570-8.

136. Zhang J, Wang LQ, Wang HJ, Tu KH. Micellization phenomena of amphiphilic block copolymers based on methoxy poly(ethylene glycol) and either crystalline or amorphous poly(caprolactone-blactide). Biomacromolecules. 2006;7:2492-500.

137. Rijcken CJ, Snel CJ, Schiffelers RM, van Nostrum CF, Hennink WE. Hydrolysable core-crosslinked thermosensitive polymeric micelles: synthesis, characterisation and in vivo studies. Biomaterials. 2007;28:5581-93.

138. O'Reilly RK, Hawker CJ, Wooley KL. Cross-linked block copolymer micelles: functional nanostructures of great potential and versatility. Chem Soc Rev. 2006;35:1068-83.

139. Hu FQ, Ren GF, Yuan H, Du YZ, Zeng S. Shell cross-linked stearic acid grafted chitosan oligosaccharide self-aggregated micelles for controlled release of paclitaxel. Colloids Surf B Biointerfaces. 2006;50:97-103.

140. Lokitz BS, Convertine AJ, Ezell RG, Heidenreich A, Li YT, McCormick CL. Responsive nanoassemblies via interpolyelectrolyte complexation of amphiphilic block copolymer micelles. Macromolecules. 2006;39:8594-602.

141. Marin A, Muniruzzaman M, Rapoport N. Mechanism of the ultrasonic activation of micellar drug delivery. J Control Release. 2001;75:69-81.

142. Husseini GA, Pitt WG. Ultrasonic-activated micellar drug delivery for cancer treatment. J Pharm Sci. 2009;98:795-811.

143. Husseini GA, Runyan CM, Pitt WG. Investigating the mechanism of acoustically activated uptake of drugs from Pluronic micelles. BMC Cancer. 2002;2:20.

144. Bohmer MR, Klibanov AL, Tiemann K, Hall CS, Gruell H, Steinbach OC. Ultrasound triggered image-guided drug delivery. Eur J Radiol. 2009;70:242-53.

145. Husseini GA, Myrup GD, Pitt WG, Christensen DA, Rapoport NY. Factors affecting acoustically triggered release of drugs from polymeric micelles. J Control Release. 2000;69:43-52.

146. Husseini GA, Pitt WG. Micelles and nanoparticles for ultrasonic drug and gene delivery. Adv Drug Deliv Rev. 2008;60:1137-52.

147. Husseini GA, Pitt WG, Christensen DA, Dickinson DJ. Degradation kinetics of stabilized Pluronic micelles under the action of ultrasound. J Control Release. 2009;138:45-8.

148. Marin A, Sun H, Husseini GA, Pitt WG, Christensen DA, Rapoport NY. Drug delivery in pluronic micelles: effect of highfrequency ultrasound on drug release from micelles and intracellular uptake. J Control Release. 2002;84:39-47.

149. Husseini GA, Pitt WG. The use of ultrasound and micelles in cancer treatment. J Nanosci Nanotechnol. 2008;8:2205-15.

150. Munshi N, Rapoport N, Pitt WG. Ultrasonic activated drug delivery from Pluronic P-105 micelles. Cancer Lett. 1997;1 18:139.

151. Husseini GA, Christensen DA, Rapoport NY, Pitt WG. Ultrasonic release of doxorubicin from Pluronic P105 micelles stabilized with an interpenetrating network of N,N-diethylacrylamide. J Control Release. 2002;83:303-5.

152. Pruitt JD, Husseini G, Rapoport N, Pitt MG. Stabilization of pluronic P-105 micelles with an interpenetrating network of N, N-diethylacrylamide. Macromolecules. 2000;33:9306-9.
153. Nelson JL, Roeder BL, Carmen JC, Roloff F, Pitt WG. Ultrasonically activated chemotherapeutic drug delivery in a rat model. Cancer Res. 2002;62:7280-3.

154. Husseini GA, O’Neill KL, Pitt WG. The comet assay to determine the mode of cell death for the ultrasonic delivery of doxorubicin to human leukemia (HL-60 Cells) from Pluronic P105 micelles. Technol Cancer Res Treat. 2005;4:707-11.

155. Husseini GA, El-Fayoumi RI, O'Neill KL, Rapoport NY, Pitt WG. DNA damage induced by micellar-delivered doxorubicin and ultrasound: comet assay study. Cancer Lett. 2000;154:211-6.

156. Rapoport N. Combined cancer therapy by micellar-encapsulated drug and ultrasound. Int J Pharm. 2004;277:155-62.

157. Pruitt JD, Pitt WG. Sequestration and ultrasound-induced release of doxorubicin from stabilized Pluronic P105 micelles. Drug Deliv. 2002;9:253-8.

158. Gao Z, Fain HD, Rapoport N. Ultrasound-enhanced tumor targeting of polymeric micellar drug carriers. Mol Pharm. 2004;1:317-30.

159. Gao ZG, Fain HD, Rapoport N. Controlled and targeted tumor chemotherapy by micellar-encapsulated drug and ultrasound. J Control Release. 2005;102:203-22.

160. Rapoport NY, Christensen DA, Fain HD, Barrows L, Gao Z. Ultrasound-triggered drug targeting of tumors in vitro and in vivo. Ultrasonics. 2004;42:943-50.

161. Husseini GA, Diaz de la Rosa MA, Gabuji T, Zeng Y, Christensen DA, Pitt WG. Release of doxorubicin from unstabilized and stabilized micelles under the action of ultrasound. J Nanosci Nanotechnol. 2007;7:1028-33.

162. Myhr G, Moan J. Synergistic and tumour selective effects of chemotherapy and ultrasound treatment. Cancer Lett. 2006;232:206-13.

163. Wang J, Pelletier M, Zhang H, Xia H, Zhao Y. High-frequency ultrasound-responsive block copolymer micelle. Langmuir. 2009;25:13201-5.

164. Zhang H, Xia H, Wang J, Li Y. High intensity focused ultrasound-responsive elease behavior of PLA-b-PEG copolymer micelles. J Control Release. 2009;139:31-9.

165. Enholm JK, Kohler MO, Quesson B, Mougenot C, Moonen CT, Sokka SD. Improved volumetric MR-HIFU ablation by robust binary feedback control. IEEE Trans Biomed Eng. 2010;57:103-13.

166. Kohler MO, Mougenot C, Quesson B, Enholm J, Le BB, Laurent $\mathrm{C}$, et al. Volumetric HIFU ablation under 3D guidance of rapid MRI thermometry. Med Phys. 2009;36:3521-35.

167. Zhao Y. Rational design of light-controllable polymer micelles. Chem Rec. 2007;7:286-94.

168. Wu G, Mikhailovsky A, Khant HA, Fu C, Chiu W, Zasadzinski JA. Remotely triggered liposome release by near-infrared light absorption via hollow gold nanoshells. J Am Chem Soc. 2008;130:8175-7.

169. Goodwin AP, Mynar JL, Ma Y, Fleming GR, Frechet JM. Synthetic micelle sensitive to IR light via a two-photon process. J Am Chem Soc. 2005;127:9952-3.

170. Lee HI, Wu W, Oh JK, Mueller L, Sherwood G, Peteanu L, et al. Light-induced reversible formation of polymeric micelles. Angew Chem Int Ed Engl. 2007;46:2453-7.

171. varez-Lorenzo G, Bromberg L, Concheiro A. Light-sensitive intelligent drug delivery systems. Photochem Photobiol. 2009;85:848-60.

172. Mayer G, Heckel A. Biologically active molecules with a "light switch". Angew Chem Int Ed Engl. 2006;45:4900-21.

173. Tong X, Wang G, Soldera A, Zhao Y. How can azobenzene block copolymer vesicles be dissociated and reformed by light? J Phys Chem B. 2005;109:20281-7.

174. Irie M. Diarylethenes for memories and switches. Chem Rev. 2000;100:1685-716. 
175. Yokoyama Y. Fulgides for memories and switches. Chem Rev. 2000;100:1717-40.

176. Feringa BL, van Delden RA, Koumura N, Geertsema EM. Chiroptical molecular switches. Chem Rev. 2000;100:1789-816.

177. Jiang J, Tong X, Zhao Y. A new design for light-breakable polymer micelles. J Am Chem Soc. 2005;127:8290-1.

178. Babin J, Pelletier M, Lepage M, Allard JF, Morris D, Zhao Y. A new two-photon-sensitive block copolymer nanocarrier. Angew Chem Int Ed Engl. 2009;48:3329-32.

179. McCoy CP, Rooney C, Edwards CR, Jones DS, Gorman SP. Light-triggered molecule-scale drug dosing devices. J Am Chem Soc. 2007;129:9572-3.

180. Bae Y, Jang WD, Nishiyama N, Fukushima S, Kataoka K. Multifunctional polymeric micelles with folate-mediated cancer cell targeting and $\mathrm{pH}$-triggered drug releasing properties for active intracellular drug delivery. Mol Biosyst. 2005;1:242-50.

181. Bae Y, Nishiyama N, Kataoka K. In vivo antitumor activity of the folate-conjugated $\mathrm{pH}$-sensitive polymeric micelle selectively releasing adriamycin in the intracellular acidic compartments. Bioconjug Chem. 2007;18:1131-9.

182. Kim D, Gao ZG, Lee ES, Bae YH. In viwo evaluation of doxorubicin-loaded polymeric micelles targeting folate receptors and early endosomal $\mathrm{pH}$ in drug-resistant ovarian cancer. Mol Pharm. 2009;6:1353-62.

183. Sethuraman VA, Bae YH. TAT peptide-based micelle system for potential active targeting of anti-cancer agents to acidic solid tumors. J Control Release. 2007;118:216-24.

184. Lee ES, Gao Z, Kim D, Park K, Kwon IC, Bae YH. Super pHsensitive multifunctional polymeric micelle for tumor $\mathrm{pH}(\mathrm{e})$ specific TAT exposure and multidrug resistance. J Control Release. 2008;129:228-36.
185. Yang X, Grailer JJ, Pilla S, Steeber DA, Gong S. Tumortargeting, $\mathrm{pH}$-responsive, and stable unimolecular micelles as drug nanocarriers for targeted cancer therapy. Bioconjug Chem. 2010;21:496-504.

186. Wu XL, Kim JH, Koo H, Bae SM, Shin H, Kim MS, et al. Tumor-targeting peptide conjugated $\mathrm{pH}$-responsive micelles as a potential drug carrier for cancer therapy. Bioconjug Chem. 2010;21:208-13.

187. Rossin R, Pan D, Qi K, Turner JL, Sun X, Wooley KL, et al. 64Cu-labeled folate-conjugated shell cross-linked nanoparticles for tumor imaging and radiotherapy: synthesis, radiolabeling, and biologic evaluation. J Nucl Med. 2005;46:1210-8.

188. Guthi JS, Yang SG, Huang G, Li S, Khemtong C, Kessinger CW, et al. MRI-visible micellar nanomedicine for targeted drug delivery to lung cancer cells. Mol Pharm. 2010;7:32-40.

189. Nasongkla N, Bey E, Ren J, Ai H, Khemtong C, Guthi JS, et al. Multifunctional polymeric micelles as cancer-targeted, MRIultrasensitive drug delivery systems. Nano Lett. 2006;6:2427-30.

190. Hong G, Yuan R, Liang B, Shen J, Yang X, Shuai X. Folatefunctionalized polymeric micelle as hepatic carcinoma-targeted, MRI-ultrasensitive delivery system of antitumor drugs. Biomed Microdevices. 2008;10:693-700.

191. Woods M, Donald EWC, Sherry AD. Paramagnetic lanthanide complexes as PARACEST agents for medical imaging. Chem Soc Rev. 2006;35:500-11.

192. Ward KM, Aletras AH, Balaban RS. A new class of contrast agents for MRI based on proton chemical exchange dependent saturation transfer (CEST). J Magn Reson. 2000;143:79-87.

193. Terreno E, StancanelloJ, Longo D, Castelli DD, Milone L, Sanders HM, et al. Methods for an improved detection of the MRI-CEST effect. Contrast Media Mol Imaging. 2009;4:237-47. 